\title{
LOS PUNTOS CLAVES PARA LA COMUNICACIÓN POR MEDIOS MATERIALES DURANTE EL HOLOCENO TARDÍO EN EL CENTRO-OESTE DE SANTA CRUZ (PATAGONIA MERIDIONAL, ARGENTINA)
}

\author{
THE KEY POINTS FOR COMMUNICATION BY MATERIAL MEANS \\ DURING THE LATE HOLOCENE IN CENTRAL-WEST SANTA CRUZ \\ (SOUTHERN PATAGONIA, ARGENTINA)
}

Anahí Rea , Francisco Guichón ${ }^{B}$, Mariana Espinosa ${ }^{C}$ \& Lara Martínez ${ }^{D}$

Se estudian puntos claves en el espacio para la comunicación por medios materiales durante los últimos 2500 años en Patagonia meridional. Se caracterizan los sitios con mayor cantidad de motivos rupestres en la meseta del Strobel (Argentina) considerando cuatro ejes: emplazamientos seleccionados, intensidad de producción rupestre, variedad de información comunicada y lapsos temporales representados. Se busca comprender los criterios de selección de estos espacios y de las estrategias de circulación de información en este período. Se evalúa la importancia de estos sitios en una escala espacial amplia y se resalta su relevancia para comprender los circuitos de comunicación entre poblaciones humanas durante el Holoceno Tardío.

Palabras clave: arte rupestre, comunicación, estrategias, cazadores-recolectores, Patagonia, Holoceno Tardío.

Key points in space for communication by material means during the last 2500 years in southern Patagonia are studied. The sites with the greatest number of rock art motifs on the Strobel plateau (Argentina) are characterized in terms of four axes: the selected locations, the intensity of rock art production, the variety of information communicated, and the time periods represented. We seek to understand the criteria for the selection of these spaces and the strategies related to the circulation of information during this period of time. The importance of these sites in a wide spatial scale is evaluated, and their relevance for the understanding of the communication circuits among human populations during the Late Holocene is highlighted.

Keywords: rock art, communication, strategies, huntergatherers, Patagonia, Late Holocene.

\section{INTRODUCCIÓN}

En la Patagonia meridional se han registrado una gran cantidad de sitios con altas frecuencias de representaciones rupestres asignadas a diferentes momentos de los últimos 10.000 años. En este artículo se profundiza en aquellos que puedan ser entendidos como puntos claves para la comunicación por medios materiales durante el Holoceno Tardío (últimos 2500 años). Para ser considerados puntos claves en una escala espacial amplia, en este trabajo se plantea que en dichos espacios se debe haber dado una intensa producción rupestre, lo cual se evidencia a partir de numerosos eventos de ejecución de motivos (ver desarrollo en Aspectos teórico-metodológicos). En este sentido, se identificaron sitios que reúnen estas características y se los comparó por medio de distintos ejes y variables con el fin de avanzar en la comprensión de los criterios de selección de estos espacios y las estrategias de circulación de información durante este lapso temporal.

Este trabajo se focaliza en el centro-oeste de la provincia de Santa Cruz, en particular en la meseta del Strobel (fig. 1). Esta meseta ha sido objeto de continuas investigaciones arqueológicas durante 20 años (Re et al. 2017), las cuales han permitido reconocer su importancia

\footnotetext{
A Anahí Re, INAPL-CONICET-UbA, Buenos Aires, Argentina. orcid: 0000-0003-2091-6983. E-mail: anahire1@gmail.com

B Francisco Guichón, CONAE-CONICET-INAPL, Buenos Aires, Argentina. ORCID: 0000-0003-4877-2555. E-mail: guichonf@gmail.com

C Mariana Espinosa, INAPL, Buenos Aires, Argentina. ORCID: 0000-0002-1148-0279. E-mail: mariannaespinosaa@gmail.com

D Lara Martínez, INAPL, Buenos Aires, Argentina. orCiD: 0000-0002-1863-8868. E-mail: laranahirmartinez1@gmail.com
} 


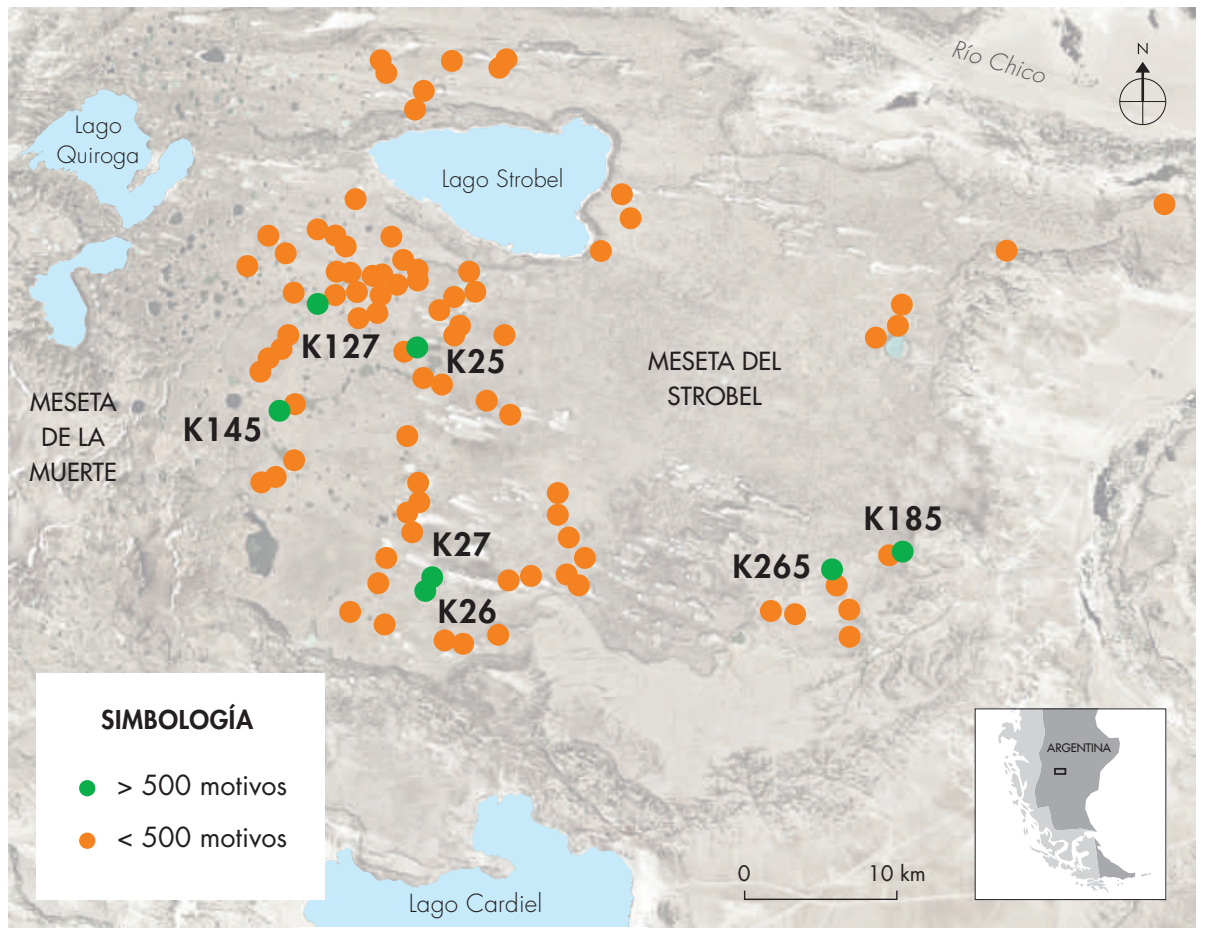

Figura 1. Ubicación de la meseta del Strobel y de los siete sitios con representaciones rupestres que se analizan en este trabajo. En naranja los restantes sitios con motivos registrados en la meseta. Figure 1. Location of the Strobel plateau and of the seven sites with rock art manifestations analyzed in this article. In orange, the remaining sites with rock art recorded on the plateau. para los grupos cazadores-recolectores como espacio de comunicación mediante representaciones rupestres en una escala macrorregional (Belardi \& Goñi 2006; Re 2010; Goñi et al. 2014; Re et al. 2017, entre otros). Se postuló la convergencia poblacional en dicha área durante los últimos 2500 años por parte de grupos provenientes de distintas regiones cercanas (Belardi \& Goñi 2006; Re 2010).

El desarrollo de las investigaciones en la meseta del Strobel ha dejado en evidencia diferencias en su interior, en cuanto a la distribución de las representaciones rupestres, indicando un uso heterogéneo del espacio para la circulación de información. Se planteó una mayor jerarquización en los circuitos de comunicación de los sectores más altos (superiores a $800 \mathrm{msnm}$ ) ubicados en el centro-oeste de esta meseta (Re et al. 2019). Adicionalmente, a partir de la comparación entre diversos sitios, se destacó la presencia de unos pocos que concentran una mayor cantidad y diversidad de representaciones (Re 2010; Re et al. 2017; Guichón 2018; Re et al. 2019, entre otros). Estos antecedentes revelan la existencia de ciertos espacios al interior de esta región que han sido privilegiados por las poblaciones humanas para la ejecución de motivos rupestres.

El principal objetivo del presente trabajo es definir las características de los puntos claves para la circulación de información en la meseta del Strobel a partir de la discusión de cuatro ejes: emplazamientos seleccionados, intensidad de producción rupestre, variedad de información comunicada y lapsos temporales representados. Esto se aborda mediante la comparación de los siete sitios con mayor cantidad de representaciones rupestres por medio de numerosas variables. Los resultados obtenidos son contrastados con otros sitios que presentan alta densidad de motivos rupestres en la Patagonia meridional. Así, se evalúa la importancia de los espacios analizados en una escala espacial amplia y su relevancia para comprender los circuitos de comunicación entre poblaciones humanas durante el Holoceno Tardío.

\section{LA MESETA}

El centro-oeste de la provincia de Santa Cruz se caracteriza por presentar un sistema de mesetas altas basálticas paralelas a la cordillera de los Andes, que son interrumpidas por cuencas de lagos y grandes ríos. La meseta del Strobel está delimitada hacia el norte y el este por el valle del río Chico, hacia el sur por la cuenca del lago Cardiel y al oeste por la meseta de la Muerte (fig. 1). Conforma una superficie basáltica de $3000 \mathrm{~km}^{2}$ 


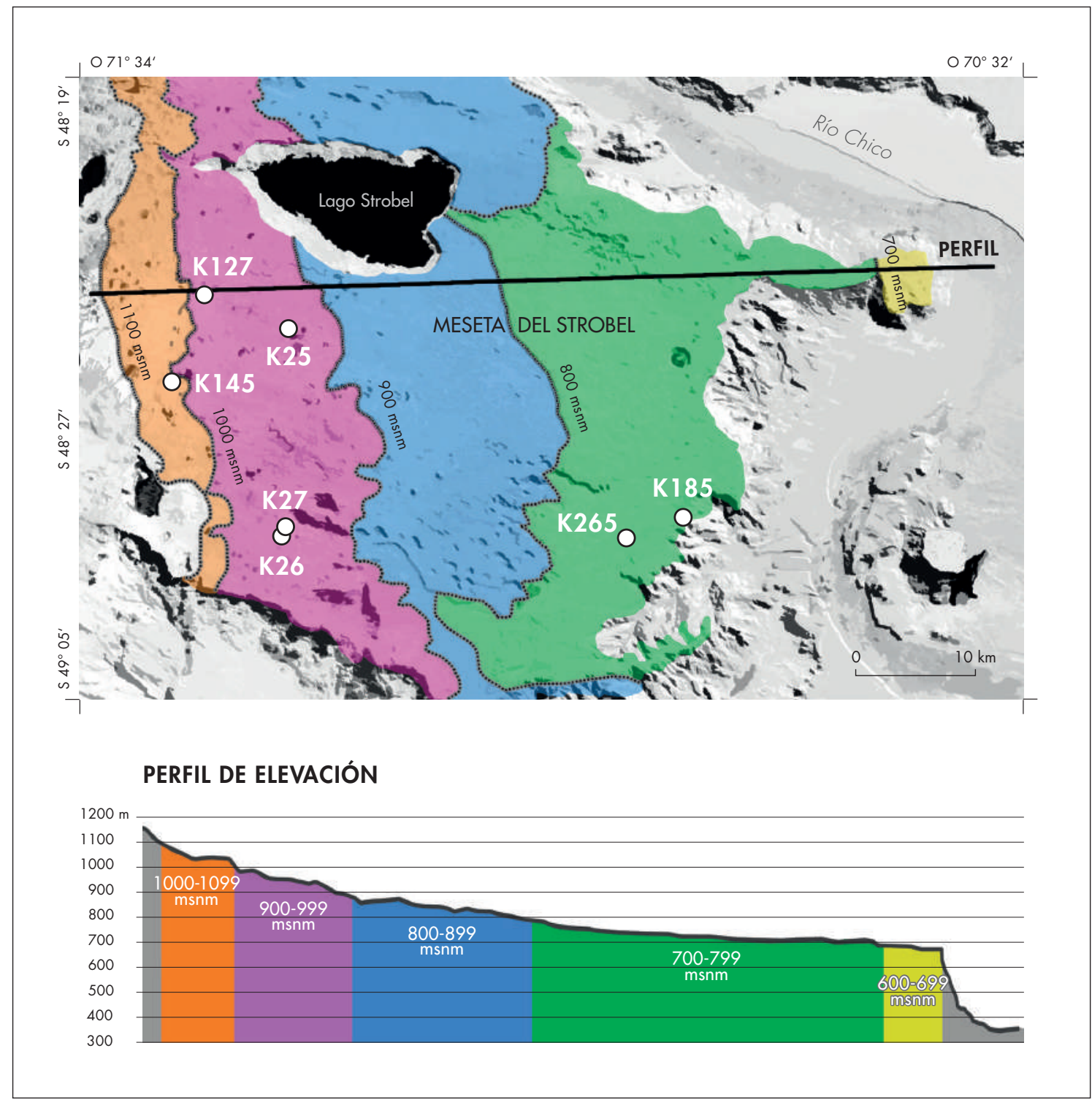

Figura 2. Ubicación de los sitios bajo estudio y rangos altitudinales de la meseta. Figure 2. Location of the sites under study and altitudinal ranges of the plateau.

con altitudes entre 650 y $1200 \mathrm{msnm}$, aumentando gradualmente de este a oeste (fig. 2).

La meseta del Strobel presenta una marcada estacionalidad que hace difícil su habitabilidad durante el invierno debido a la cobertura de nieve y el descenso de la temperatura. En cambio, la estación estival cuenta con una gran disponibilidad de agua proveniente del deshielo y el desarrollo de pasturas nuevas que atraen a guanacos (Lama guanicoe) y aves. En términos gene- rales, la meseta se caracteriza por un ambiente árido semidesértico con un clima templado-frío dominado por una estepa herbácea (Cabrera \& Willink 1980). Las precipitaciones fluctúan entre 200 y $400 \mathrm{~mm}$ anuales (Oliva et al. 2001). Además, soplan vientos intensos del oeste -denominados Southern Westerlies-, establecidos hace 6000 años AP, con un incremento en la intensidad durante el Holoceno Tardío (Gilli et al. 2005). 
En la meseta se ubican los lagos Strobel, Quiroga Grande y Quiroga Chico, el río Barrancoso y una gran cantidad de lagunas de diversos tamaños (figs. 1 y 2). Estas últimas se encuentran en depresiones naturales del basalto y son alimentadas por el derretimiento de la nieve y la percolación del agua, por lo que presentan importantes variaciones (300 a 2000 según el año) (Lancelotti 2009). La disponibilidad de agua no es homogénea, permitiendo destacar el sector oeste (más de $900 \mathrm{msnm}$ ) por su gran capacidad de reserva de agua (Lancelotti 2009).

Con respecto a la vegetación, se observa un predominio de matas gramíneas y arbustos de baja y media altura (Cabrera \& Willink 1980). Sin embargo, su distribución no es uniforme, contando con un mayor porcentaje de cobertura vegetal sobre el oeste y un suelo desnudo en el este (Lancelotti 2009). En los lugares reparados del sector este se registra la presencia de arbustos leñosos, los cuales son escasos sobre los $900 \mathrm{msnm}$ (Oliva et al. 2001; Re et al. 2019). Cabe destacar el desarrollo de microambientes de vegas o mallines generados por vertientes de agua menores en sectores puntuales.

$\mathrm{Al}$ interior de la meseta del Strobel se distinguen sectores con diversas características topográficas que incluyen: pampas altas, bajos con y sin lagunas, cañadones y bordes de meseta (fig. 3) (Re 2010; Flores Coni 2018; Guichón 2018). Las pampas altas son el rasgo predominante de la superficie plana o levemente ondulada de mayor altitud relativa y de donde se logra una amplia visión del entorno. En ellas se encuentra escaso reparo, representado por paredones aislados bajos. En cuanto a los bajos con y sin lagunas, estos corresponden a depresiones naturales que están rodeadas generalmente por paredones basálticos y constituyen la mayor fuente de reparos y soporte para las representaciones rupestres. En muchos casos, estos espacios presentan lagunas permanentes o temporales y una gran diversidad de tamaños que varían desde ca. $0,006 \mathrm{~km}^{2}$ a $10 \mathrm{~km}^{2}$ o más. Por su parte, el curso del río Barrancoso forma un cañadón de más de $26 \mathrm{~km}$ de longitud con una orientación suroeste-noreste. A lo largo del mismo se desarrollan paredones basálticos con altura variable. En algunos sectores se forman amplias vegas con una superficie plana. Finalmente, en los bordes de meseta se desarrollan paredones discontinuos, los cuales, en determinados lugares, se ubican grandes vegas o mallines vinculados a vertientes alimentadas por percolación de agua.

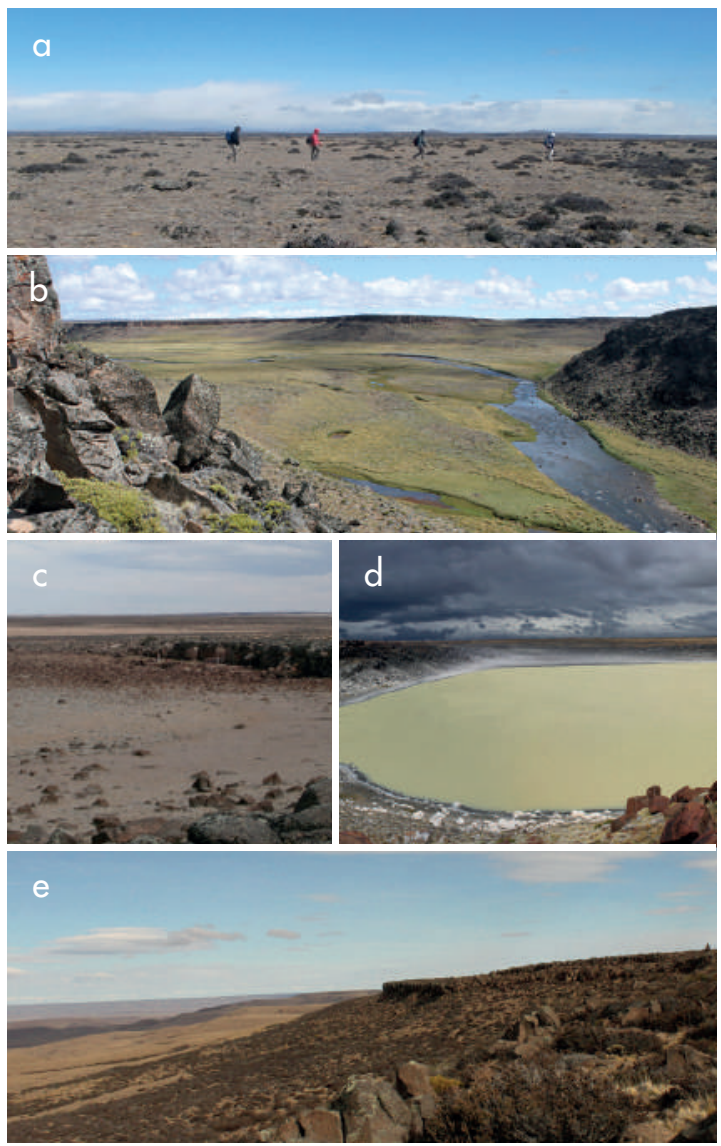

Figura 3. Sectores de la meseta con distintas características topográficas: a) pampa alta; b) cañadón; c) bajo con laguna seca; d) bajo con laguna; e) borde de meseta. Figure 3. Areas of the plateau with different topographical features: $\boldsymbol{a}$ ) high pampa; $\boldsymbol{b}$ ) canyon; c) depression with dried lagoon; d) depression with lagoon; e) edge of plateau.

La casi total ausencia de rasgos topográficos identificables a grandes distancias dificulta la orientación. Tanto los bajos como el cañadón del río Barrancoso se pierden sobre el horizonte y solo pueden ser reconocidos a corta distancia. Las únicas excepciones están dadas por conos volcánicos erosionados (máximo $70 \mathrm{~m}$ de altura) ubicados en el sur de la meseta y visibles desde una distancia menor a $12 \mathrm{~km}$. A su vez, elevaciones en regiones cercanas, como la meseta de la Muerte o el cerro San Lorenzo, pueden ser observadas en un día despejado y sirven como referencia general.

En síntesis, si bien la meseta se presenta a primera vista como un espacio homogéneo, evidencia importantes diferencias internas dependiendo de la altitud, el clima, la disponibilidad de recursos (agua, vegetación, reparo) 
y el potencial control visual del entorno. Se desprende, entonces, que estas características incidieron e inciden actualmente en la selección de espacios por parte de las poblaciones humanas.

\section{ANTECEDENTES}

Las investigaciones realizadas durante 20 años en la meseta del Strobel proponen su incorporación efectiva a los circuitos de movilidad de los cazadores-recolectores durante el Holoceno Tardío como un espacio de uso logístico o estacional articulado con cuencas bajas como, por ejemplo, el lago Cardiel. De forma complementaria, se ha sugerido su importancia para la comunicación por medios materiales y en términos de convergencia poblacional a escala macrorregional (Belardi \& Goñi 2006; Re 2010; Goñi et al. 2014; Re et al. 2017). Esta convergencia poblacional es entendida como el nucleamiento en un mismo espacio de segmentos poblacionales provenientes de diferentes lugares. Así, la meseta sería un espacio de potencial uso común, ya sea en forma diferida o simultánea. Una de las claves de esta discusión es la programación de uso del espacio (Goñi et al. 2014). Estas propuestas permiten explicar el registro arqueológico de la meseta, caracterizado por fechados radiocarbónicos concentrados entre los 1200 y 400 años Ap, el equipamiento del espacio mediante estructuras de caza y la alta frecuencia y variedad de representaciones rupestres (Re et al. 2017). Diversas evidencias indican que la colonización de esta área se habría iniciado previamente durante el Holoceno Medio (Goñi et al. 2014; Re et al. 2017).

En la meseta del Strobel se han registrado 107 sitios con representaciones rupestres, incluyendo los trabajos de campo del año 2020 (fig. 1). Estos sitios se distribuyen de forma heterogénea en la meseta y presentan una gran diversidad en cuanto a cantidad y variedad de motivos (Goñi et al. 2014; Re et al. 2017). El uso diverso y la jerarquización del espacio dentro de la meseta constituyen temas de interés que han sido abordados en varias oportunidades. En una primera aproximación y con una muestra de 30 sitios, Re y Guichón (2009) evaluaron el uso diferencial de los sectores norte y sur. Como resultado observaron grandes similitudes entre ambos sectores e identificaron, tanto al norte como al sur, sitios de diversas dimensiones, incluyendo algunos con más de 500 motivos. Posteriormente, Re y colaboradores (2019) consideraron la distribución de motivos rupestres y sus características en un eje esteoeste sobre el sector norte de la meseta. Registraron una mayor cantidad de sitios con alta densidad y variedad de motivos en el centro-oeste a más de $800 \mathrm{msnm}$, lo cual llevó a proponer su jerarquización para la circulación de información (Re et al. 2019).

El análisis de variables, como grados de pátina, superposiciones y el desvaído de la pintura, permitió generar una secuencia relativa de ejecución de los tipos de motivos y asociarla a los distintos momentos de ocupación antes mencionados (Re 2010; Guichón et al. 2016; Guichón 2018). La asignación cronológica de cada uno de los lapsos identificados en la secuencia de producción rupestre se sustenta en diversas evidencias: fechados radiocarbónicos, tecnologías y artefactos asociados, morfologías diagnósticas de ciertos motivos según las propuestas regionales, sellos arqueológicos sobre grabados, referentes conocidos, etcétera (Re 2010; Guichón et al. 2016; Guichón 2018).

Se distinguió un primer momento de ejecución asociable al Holoceno Medio, caracterizado por bajas frecuencias y diversidad de motivos grabados, los que incluyen algunos abstractos (reticulados, líneas rectas paralelas, círculos y líneas sinuosas) y siluetas de guanaco. Estas últimas son estáticas y con cuerpos desarrollados (grupo de diseño 1; sensu Re 2010, 2017), similares a las definidas para los grupos estilísticos B y B1 del área Río Pinturas y Parque Nacional Perito Moreno (Gradin 1983; Aschero 1996). Para el Holoceno Tardío se distinguen al menos tres momentos de ejecución. Durante el primero, se mantienen los motivos representados en el lapso temporal previo y se incorporan representaciones zoomorfas, antropomorfas y abstractas (matuasto, huella de felino, huella humana, banda, punteados, entre otras). En el segundo, se abandonan los motivos característicos del Holoceno Medio y se agregan nuevos figurativos y abstractos (escena, espiral, cruz, entre otros). A partir de los indicadores mencionados, este período fue vinculado con la intensificación de las ocupaciones humanas de la meseta a partir de ca. 1000 años AP. Estos últimos dos momentos se caracterizan, además, por la incorporación de la pintura como técnica de ejecución poco frecuente. Por último, en el tercero se han registrado grabados que pueden vincularse a los primeros contactos con las poblaciones europeas en los siglos XVI y XVII (figuras y huellas de caballo, entre otros) (Re et al. 2010a). ${ }^{1}$ 

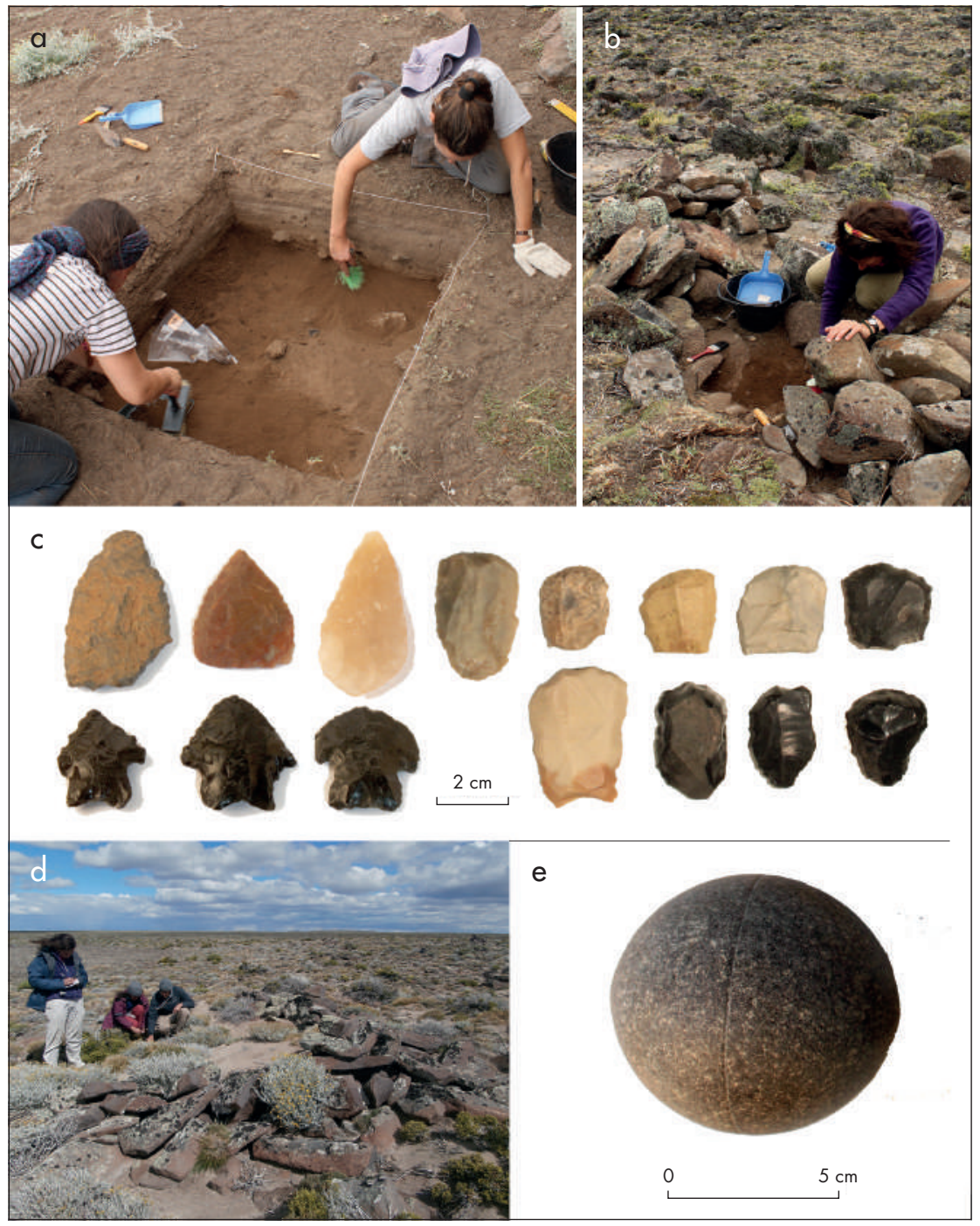

Figura 4. Registro arqueológico de la meseta del Strobel: a) excavación de sector asociado a paredón en sitio K127; b) excavación de parapeto en sitio K116; c) artefactos líticos más comunes (puntas de proyectil y raspadores); d) parapeto de caza en sitio K106; e) bola de boleadora. Figure 4. Strobel plateau archaeological record: a) excavation near $\mathrm{K} 127$ rock wall; $\boldsymbol{b})$ hunting blind excavation at K116; c) most common lithic artifacts (projectile points and scrapers); d) hunting blind in $\mathrm{K106}$ e) stone bolas.
En este trabajo se comparan los siete sitios con mayor cantidad de motivos, es decir, aquellos que cuentan con más de 500. El estudio del arte rupestre de algunos de ellos como K25, K26, K27 y K145 fue presentado previamente (Re 2010; Goñi et al. 2014; Re et al. 2017; Guichón 2018; Re et al. 2019; Martínez 2021, entre otros); otros han sido mencionados brevemente, como es el caso de K127 y K185 (Re et al. 2017; Flores Coni et al. 2019; Re et al. 2019), y K265 ha sido recientemente identificado. Así, por un lado, se resume información ya publicada y, por otro, se presentan datos inéditos producto del estudio de nuevas variables y de relevamientos en sitios conocidos previamente y en aquellos registrados en las últimas campañas. En todos los sitios aquí analizados se han registrado otros materiales asociados, como artefactos líticos (raspadores, puntas de proyectil, etc.) y parapetos de caza (fig. 4). ${ }^{2} \mathrm{El}$ estado actual de los análisis sugiere que con los mismos se realizaron distintas actividades relacionadas con la obtención y el procesamiento de presas animales durante la primavera y verano. Por ejemplo, mientras en K25 se ha destacado el predominio de las últimas etapas de confección y la reactivación de instrumentos líticos, en K127 se ha detectado, a su vez, la presencia de tareas de raspado del cuero de los guanacos y el procesamiento de materiales (Flores Coni 2018). 


\section{ASPECTOS TEÓRICO-METODOLÓGICOS}

Diversos medios materiales han sido utilizados por las poblaciones humanas para comunicarse. Este trabajo se focaliza en aquellos materiales asignados al Holoceno Tardío que presentan imágenes pintadas o grabadas. En el caso de la Patagonia continental meridional esto implica centrarse en las representaciones rupestres, ya que solo se ha documentado una muy baja cantidad de artefactos móviles con este tipo de diseños, tales como placas, cerámica y molinos (ver discusión de estos materiales en Cassiodoro et al. 2019). ${ }^{3}$ Se entiende que la mayor parte de las representaciones rupestres de la región pueden ser comprendidas como una forma de comunicación o circulación de información entre distintos grupos humanos o individuos (Aschero 1996; Carden 2008; Re 2010; Guichón 2018; Cordero et al. 2019; Acevedo \& Fiore 2020; González Dubox et al. 2021). Se considera que los mensajes o información transmitida pudieron ser múltiples y complementarios en distintas escalas y corresponder a aspectos ecológicos, económicos, sociales e ideológicos (Re 2010).

En este artículo se evalúan las características de los puntos claves de la comunicación por medios materiales en los últimos 2500 años en la Patagonia meridional. Se define como punto clave aquellos espacios donde hubo una intensa circulación de información durante este lapso temporal, evidenciada por numerosos eventos de ejecución de motivos que destacan en una escala macrorregional. Por lo tanto, este trabajo se focalizará en la caracterización de conjuntos rupestres con una alta cantidad de motivos, así como en establecer rasgos compartidos y divergencias. El estudio de estos puntos en el espacio tiene un gran potencial para avanzar en la comprensión de los circuitos de comunicación de las poblaciones cazadoras-recolectoras del área de estudio. Para abordar esta problemática, se comparan los sitios con mayor cantidad de motivos de la meseta del Strobel, es decir, aquellos que cuentan con más de 500. La comparación y discusión se organiza en torno a cuatro ejes:

1) Emplazamientos seleccionados: permite abordar algunos de los criterios de selección de estos espacios. Se considera la ubicación de los sitios y sus características topográficas y ambientales.

2) Intensidad de producción rupestre: determina si se presentan diferencias de intensidad de uso entre ellos y también cómo fue la utilización de distintos sectores al interior de cada uno de los sitios. Dicha producción se evalúa a partir de aspectos vinculados con la frecuencia de motivos rupestres y su disposición a lo largo de los soportes (cantidad de unidades topográficas o UT $)^{4}$ Así, es posible evaluar su concentración en determinados sectores.

3) Variedad de información comunicada: permite discutir la variedad o redundancia de información potencialmente transmitida (Carden 2008; González Dubox et al. 2021). Si bien hay otros indicadores, aquí se aborda a partir de la diversidad técnica y morfológica de los motivos, considerando la potencial variedad y no específicamente qué tipo de información fue comunicada.

4) Lapsos temporales representados: evalúa el posible uso contemporáneo o complementario de los sitios luego de discutir su recorrido temporal. Se focaliza en la cronología relativa de los motivos con el objeto de comparar las tendencias temporales de los distintos sitios. Esta información es cotejada con la secuencia de ejecución previamente elaborada (Re 2010; Re et al. 2017; Guichón 2018) y la cronología de otras evidencias asociadas (fechados radiocarbónicos, diseños de artefactos, etc.).

Con fines operativos, los cuatro ejes se evalúan en función de múltiples variables, las que no agotan las posibilidades (tabla 1). Se consideran tanto variables de aplicación novedosa en el área como otras previamente utilizadas (Re 2010; Re et al. 2017; Guichón 2018), algunas de las cuales son redefinidas con el fin de lograr una mejor comparación.

\section{RESULTADOS}

\section{Muestra}

La meseta del Strobel cuenta, hasta 2020, con el registro de 270 sitios arqueológicos, de los cuales 107 contienen representaciones rupestres (fig. 1). Actualmente, 88 de estos últimos sitios han sido analizados de forma completa en laboratorio llegando a identificarse más de 10.000 motivos, tanto grabados como pintados. La mayoría de ellos corresponden a sitios con una frecuencia baja o intermedia de motivos, en tanto que solo en siete casos se registraron más de 500. Entre estos 
Tabla 1. Ejes y variables empleadas en la comparación. Table 1. Axes and variables used for comparison.

\begin{tabular}{|c|c|c|}
\hline EJE & $\begin{array}{c}\text { VARIABLE/CONJUNTO } \\
\text { DE VARIABLES }\end{array}$ & DETALLE Y DESCRIPCIÓN \\
\hline \multirow{6}{*}{1} & Ubicación & Localización en la meseta según puntos cardinales (norte, sur, este, oeste). \\
\hline & Proximidad & Distancia mínima $(\mathrm{km})$ en línea recta que separa dos sitios con más de 500 motivos. \\
\hline & Altitud & Metros sobre el nivel del mar (msnm). \\
\hline & Situación topográfica & Uso de paredón aislado, de bajo (con y sin laguna), de cañadón o de borde de meseta. \\
\hline & Fuente de agua & $\begin{array}{l}\text { Tipo (laguna, río, mallín, etc.), estabilidad (alta, media o baja) y distancia mínima }(\mathrm{km}) \\
\text { en línea recta a una fuente de agua. }\end{array}$ \\
\hline & Reparo & $\begin{array}{l}\text { Extensión y altura de los paredones disponibles y presencia/ausencia de superficies } \\
\text { colindantes planas de más de } 2500 \mathrm{~m}^{2} \text { potencialmente utilizadas. }\end{array}$ \\
\hline \multirow{4}{*}{2} & N. ${ }^{\circ}$ de motivos & Cantidad de motivos por sitio. \\
\hline & N. ${ }^{\circ}$ de ut y conc & $\begin{array}{l}\text { Frecuencia de unidades topográficas (UT) y de concentraciones (CONC), conformadas } \\
\text { por dos o más UT separadas de otro conjunto de motivos por } 10 \text { metros o más. }\end{array}$ \\
\hline & $\begin{array}{l}\text { Densidad de motivos } \\
\text { por UT }\end{array}$ & Densidad promedio y máxima de motivos por UT. \\
\hline & $\begin{array}{l}\text { Densidad de motivos } \\
\text { por CONC }\end{array}$ & Densidad máxima por conc y proporción de motivos (\%) en la conc mayor. \\
\hline \multirow[t]{2}{*}{3} & $\begin{array}{l}\text { Morfología de } \\
\text { motivos }\end{array}$ & $\begin{array}{l}\text { Clasificación de motivos de mayor a menor detalle según su categoría (tres categorías: } \\
\text { abstractos, zoomorfos y antropomorfos), tipo de motivo ( } 31 \text { tipos, p. e., guanaco) } \\
\text { y grupo de diseño ( } 40 \text { GD definidos en } 11 \text { tipos, p. e., guanaco GD1 o GD2) (Re 2010; Re } \\
\text { \& Guichón 2016; Re 2017; Re et al. 2017; Guichón 2018). }\end{array}$ \\
\hline & Técnica & $\begin{array}{l}\text { Técnica de confección del motivo: grabado (picado, inciso, raspado o combinación) } \\
\text { y pintura (estarcido o aplicación directa, con dedos, pincel, etc.). }\end{array}$ \\
\hline \multirow{2}{*}{4} & Grado de pátina & $\begin{array}{l}\text { Coloración del surco grabado según tres grados: pátina } 1 \text { (más oscura), pátina } 2 \\
\text { (intermedia) y pátina } 3 \text { (más clara). }\end{array}$ \\
\hline & Superposición & $\begin{array}{l}\text { Relación entre un motivo rupestre que ha sido confeccionado sobre otro que se } \\
\text { encontraba previamente en el soporte. }\end{array}$ \\
\hline
\end{tabular}

se incluyen: K25-Laguna del Faldeo Verde, K127-Vega del Flaco y K145-Laguna del Puente, en el sector norte, y K26-Laguna Uli, K27-Las Novias, K185-La Paloma (sector 2) y K265-Felicindo Nahuel, en el sur (figs. 1 y 2). ${ }^{6}$ Estos siete sitios representan menos del $10 \%$ de la muestra de sitios y, sin embargo, registran más de la mitad de los motivos rupestres documentados.

La totalidad de las variables serán evaluadas en los sitios para los que se ha completado su estudio sistemático. En aquellos aún bajo estudio, K185 y K265, algunas variables serán consideradas solamente de manera preliminar.

\section{Emplazamientos seleccionados}

En los sitios de la muestra se observa una gran diversidad en términos de su emplazamiento debido a las características topográficas y ambientales. En primera instancia, se localizan en diferentes sectores de la meseta: noroeste (K145, K127 y K25), sureste (K185 y K265) y centro-sur (K26 y K27) (figs. 1 y 2). A su vez, no se encuentran concentrados, ya que se reconoce una distancia mínima de $5 \mathrm{~km}$ lineales entre los mismos. La excepción está dada por K26 y K27 que se ubican a menos de 1 km (figs. 1 y 2). 
Tabla 2. Características de los emplazamientos seleccionados. Table 2. Features of the selected sites.

\begin{tabular}{|c|c|c|c|c|c|c|c|c|}
\hline & & \multicolumn{3}{|c|}{ SECTOR NORTE } & \multicolumn{4}{|c|}{ SECTOR SUR } \\
\hline & & K25 & K127 & K145 & K26 & K27 & K185-S2 & K265 \\
\hline \multicolumn{2}{|c|}{ Altitud (msnm) } & 933 & 961 & 1014 & 933 & 929 & 775 & 771 \\
\hline \multicolumn{2}{|c|}{ Situación topográfica } & Bajo & Cañadón & Bajo & Bajo & Gran bajo & Borde de meseta & Bajo \\
\hline \multirow{3}{*}{$\begin{array}{l}\text { Fuente } \\
\text { de agua }\end{array}$} & Tipo & Dos lagunas & Río y mallines & Laguna & Laguna & Laguna y mallín & Mallín & Laguna \\
\hline & Estabilidad & Media & Alta & Alta & Alta & Alta & Alta & Media \\
\hline & Distancia & $-50 \mathrm{~m}$ & $-50 m$ & $-50 \mathrm{~m}$ & $-50 \mathrm{~m}$ & $100 \mathrm{~m}$ & $750 \mathrm{~m}$ & $-50 \mathrm{~m}$ \\
\hline \multirow{3}{*}{ Reparo } & Extensión & $800 \mathrm{~m}$ & $400 \mathrm{~m}$ & $670 \mathrm{~m}$ & $500 \mathrm{~m}$ & $300 \mathrm{~m}$ & $100 \mathrm{~m}$ & $100 \mathrm{~m}$ \\
\hline & Altura & 3 a $6 \mathrm{~m}$ & 2 a $5 \mathrm{~m}$ & 2 a $6 \mathrm{~m}$ & 2 a $6 \mathrm{~m}$ & 4 a $8 \mathrm{~m}$ & 3 a $5 \mathrm{~m}$ & 4 a $5 \mathrm{~m}$ \\
\hline & $\begin{array}{c}\text { Superficie } \\
\text { plana asociada }\end{array}$ & Sí & Sí & Sí & Sí & Sí & Sí & Sí \\
\hline
\end{tabular}
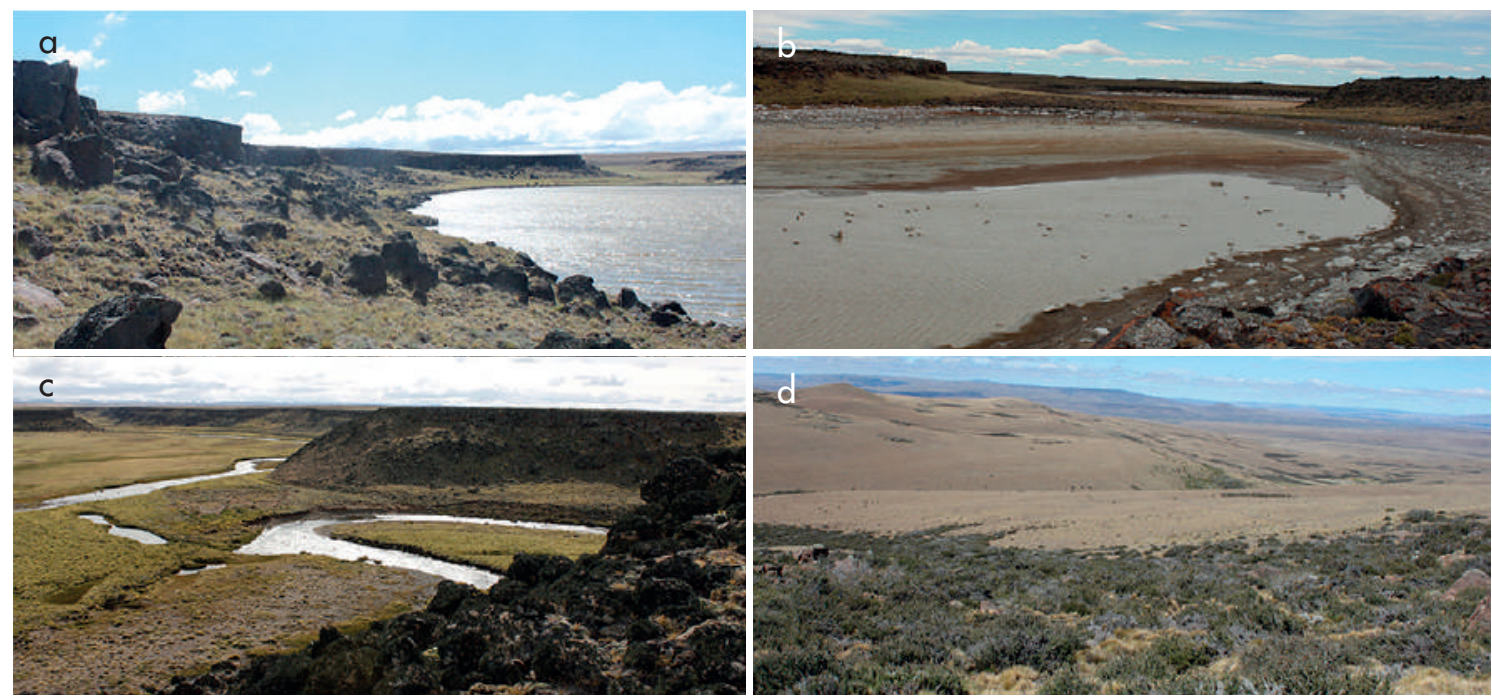

Figura 5. Fuentes de agua disponibles en proximidad a los sitios: a) laguna, sitio K145; b) laguna, sitio K25 c) río, sitio K127; d) mallín o vega, sitio K185. Figure 5. Water sources available nearby the sites: a) lagoon, site K145; b) lagoon, site K25; c) river, site K127; d) mallin or wetland, site K185.

Con respecto a la elevación, los sitios considerados están distribuidos en diversos rangos altitudinales (tabla 2, fig. 2). El más elevado corresponde a K145, ubicado a más de 1000 msnm, le siguen K25, K26, K27 y K127 que se encuentran entre los 900 y 999 msnm y, por último, K185 y K265 localizados entre los 700 y 799 msnm. Respecto de las características topográficas, con excepción de K127 y K185 donde se aprovecharon paredones de cañadón y de borde de la meseta, respectivamente (fig. 3), el resto de los sitios se ubica sobre los reparos asociados a bajos con y sin laguna actualmente (fig. 3, tabla 2). Cabe señalar que K27 está emplazado sobre un bajo que supera los $10 \mathrm{~km}^{2}$ y que contrasta con los tamaños más pequeños de las otras depresiones (fig. 3). Dada la situación topográfica de los sitios, solo pueden ser visibilizados desde distancias menores a $1 \mathrm{~km}$, con excepción de K185 ubicado en un borde de la meseta.

En relación con las fuentes de agua disponibles, la mayoría de los sitios están asociados a lagunas con alta estabilidad como el caso de K26, K27 y K145 (Lange \& Tchilinguirian 2017), mientras que otras lagunas tienen una estabilidad media (K25, K265) (Lancelotti 2009; Victoria Lange com. pers.) (fig. 5, tabla 2). En el caso de K27, si bien se encuentra asociado a un bajo 

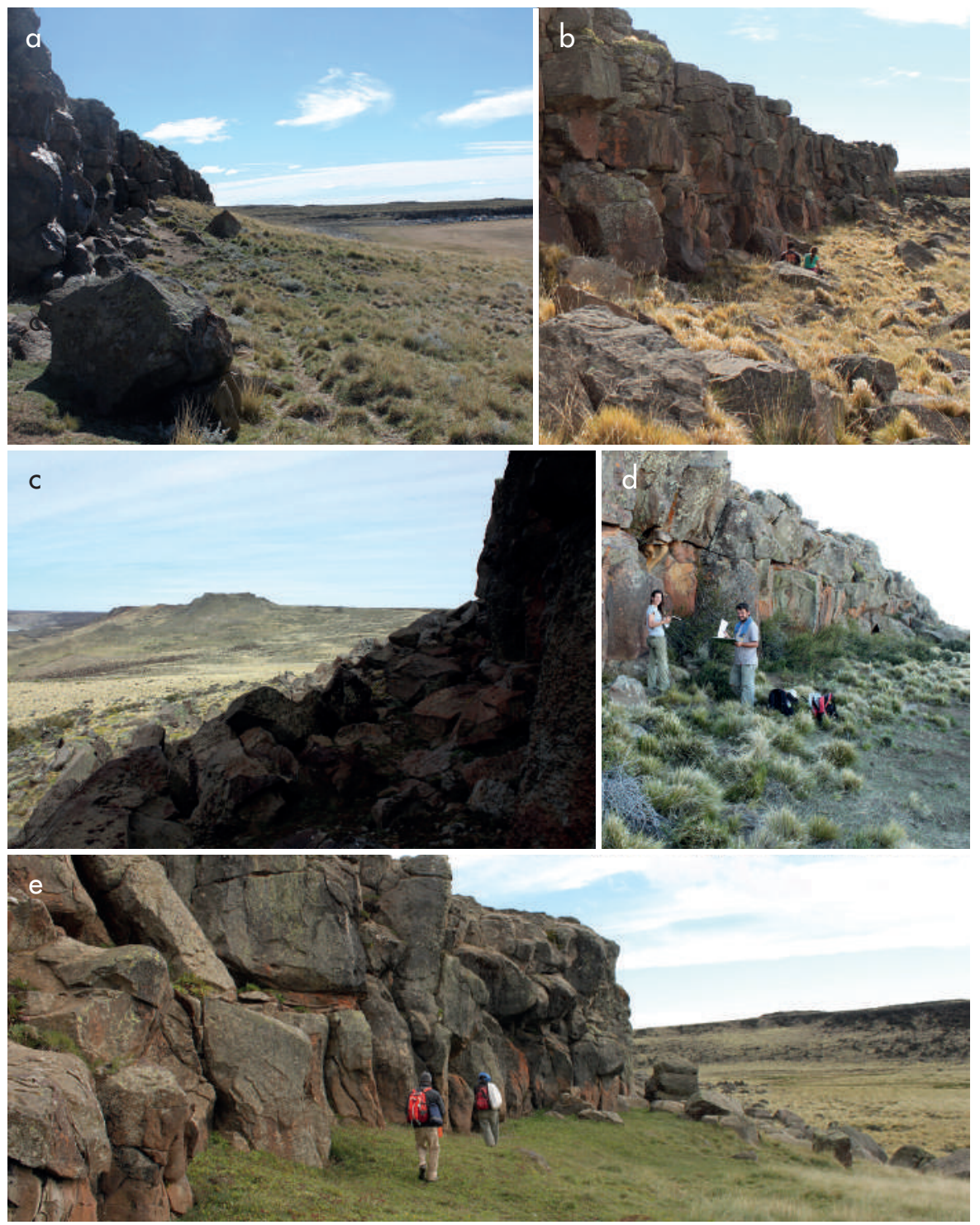

Figura 6. Reparos y soportes disponibles en cinco de los sitios analizados: a) sitio K25; b) sitio K127; c) sitio K27; d) sitio K185; e) sitio K145. Figure 6. Available rock shelters and rock supports in five of the analyzed sites: a) site $\mathrm{K} 25$; b) site $\mathrm{K} 127$; c) site $\mathrm{K} 27$; d) site K185; e) site K145.

con tres lagunas, la fuente de agua estable más cercana es un mallín o vega. Algo similar sucede en K185, sitio relacionado con un mallín de alta estabilidad. Por su parte, K127, emplazado sobre un cañadón, tiene disponibilidad permanente de agua debido a su cercanía con el río Barrancoso (fig. 5c). Estas fuentes de agua se encuentran, en general, a menos de $50 \mathrm{~m}$ de distancia de los sitios. La única excepción está dada por K185 cuya fuente de agua conocida, un mallín o vega de grandes dimensiones, se localiza a $750 \mathrm{~m}$ (fig. $5 \mathrm{~d}$ ).

Todos los sitios analizados se caracterizan por presentar un buen reparo, dado por el largo y alto de los paredones y por la superficie plana asociada (fig. 6, tabla 2). La extensión de los paredones donde estos se emplazan presenta grandes diferencias, pero siempre igualan o superan los $100 \mathrm{~m}$. En un primer grupo de sitios (K185 y K265) los paredones disponibles se extienden por $100 \mathrm{~m}$; en un segundo grupo, entre 200 y $400 \mathrm{~m}$ (K27 y K127), y el resto, supera los $500 \mathrm{~m}$ de paredón (K25, K26 y K145) (tabla 2). A su vez, todos poseen paredones altos $(2 \mathrm{a} 8 \mathrm{~m}$ ) y presentan extensas superficies planas o con pendientes poco acentuadas, colindantes a las paredes. 
Tabla 3. Variables utilizadas para discutir la intensidad de producción rupestre en los sitios bajo estudio. Referencia: ${ }^{*}$ Datos preliminares. Table 3. Variables used for the discussion of the intensity of rock-art production in the sites under study. Reference: ${ }^{*}$ Preliminary data.

\begin{tabular}{|c|c|c|c|c|c|c|c|}
\hline & \multicolumn{3}{|c|}{ SECTOR NORTE } & \multicolumn{4}{|c|}{ SECTOR SUR } \\
\hline & K25 & K127 & K145 & K26 & K27 & K185-S2 & K265 \\
\hline N. ${ }^{\circ}$ motivos & 1150 & 1256 & 1001 & 1012 & 710 & $+500^{*}$ & $+1000^{*}$ \\
\hline N.o UT & 217 & 111 & 112 & 176 & 137 & 46 & 98 \\
\hline Promedio de motivos por UT & 5,30 & 11,32 & 8,94 & 5,75 & 5,18 & $+10^{*}$ & $+10^{*}$ \\
\hline $\begin{array}{l}\text { Máxima cantidad } \\
\text { de motivos por UT }\end{array}$ & $\begin{array}{c}72 \\
\text { (UT13C-55) }\end{array}$ & $\begin{array}{c}107 \\
(\mathrm{P} 4-\mathrm{UT} 28)\end{array}$ & $\begin{array}{c}92 \\
\text { (UT74) }\end{array}$ & $\begin{array}{c}45 \\
\text { (UT32A) }\end{array}$ & $\begin{array}{c}38 \\
\text { (UT1) }\end{array}$ & $\begin{array}{l}+100^{*} \\
(\mathrm{UT} 25)\end{array}$ & $\begin{array}{l}+120^{*} \\
(\mathrm{UT} 55)\end{array}$ \\
\hline N. ${ }^{\circ} \mathrm{CONC}$ & 7 & 8 & 5 & 10 & 6 & 2 & 1 \\
\hline $\begin{array}{l}\text { Máxima cantidad de } \\
\text { motivos por conC }\end{array}$ & 923 & 556 & 538 & 769 & 428 & $\mathrm{SD}$ & $+1000^{*}$ \\
\hline$\%$ de motivos en conc mayor & 80,26 & 44,26 & 53,8 & 75,98 & 60,28 & SD & 100 \\
\hline
\end{tabular}

\section{Intensidad de producción rupestre}

Con respecto a la intensidad de producción rupestre y de acuerdo con los criterios de selección de la muestra todos los sitios cuentan con un mínimo de 500 motivos, cuatro sitios superan los 1000 (K25, K127, K145 y K26), y uno de ellos (K27) contiene 710 (tabla 3). Aunque aún no se dispone de datos finales para K185 y K265, un análisis preliminar contabiliza más de 500 motivos en el primero y más de 1000 en el segundo.

En cuanto a la cantidad de UT, se identificaron valores entre 46 (K185) y 217 (K25) (tabla 3), lo que indica una diferente distribución de los motivos al interior de los sitios considerados, relacionada en parte con la extensión de los paredones disponibles. En su mayoría, los motivos rupestres fueron realizados en más de 100 UT, valor que contrasta con los restantes sitios de la meseta, los que, en general, no superan las 20 UT (Guichón 2018; Re et al. 2019). La densidad de motivos promedio por ut varía en un rango entre 5 y 13 . No obstante, como ya ha sido observado en trabajos anteriores (Guichón 2018), todos los sitios aquí analizados exhiben una o más UT, con alta densidad de motivos, superando las 40 representaciones (figs. 7, 8 y 9).

También se consideró la distribución de las UT al interior de los sitios. En este punto se observó una gran variedad de situaciones, desde la existencia de una única concentración de UT en K265, hasta ejemplos con
10 concentraciones como en K26 (tabla 3). En aquellos sitios que presentan dos o más concentraciones, se constató asimismo una distribución heterogénea en la que una de ellas presenta frecuencias superiores a las 400 representaciones rupestres y, por lo tanto, condensa la mayoría de los motivos presentes del sitio (44\% a 80\%) (tabla 3).

En síntesis, en función de los criterios de selección de la muestra, se parte de la base de que la producción de motivos rupestres fue mucho más intensa en los siete sitios estudiados que en los 100 restantes identificados en la meseta del Strobel. A su vez, los datos presentados muestran un fuerte contraste, ya que la mayoría de los aquí analizados al menos duplica la cantidad de motivos registrados en otros sitios (más de 1000 motivos vs. menos de 500) y quintuplica el número de UT (100 UT vs. menos de 20). Asimismo, se observa una distribución heterogénea de los motivos al interior de estos sitios y se registran espacios, tanto UT como concentraciones, que agrupan una mayor cantidad de manifestaciones. En todos ellos destaca la presencia de un sector del soporte relativamente continuo con más de 400 motivos. También existen diferencias entre los sitios (p. e., extensión de soporte y cantidad de concentraciones). Más allá de las mismas, los patrones evidenciados demuestran una opción por recargar espacios con información, esto debido a la intensa ejecución de motivos rupestres, tanto a escala mesorregional como microrregional. 


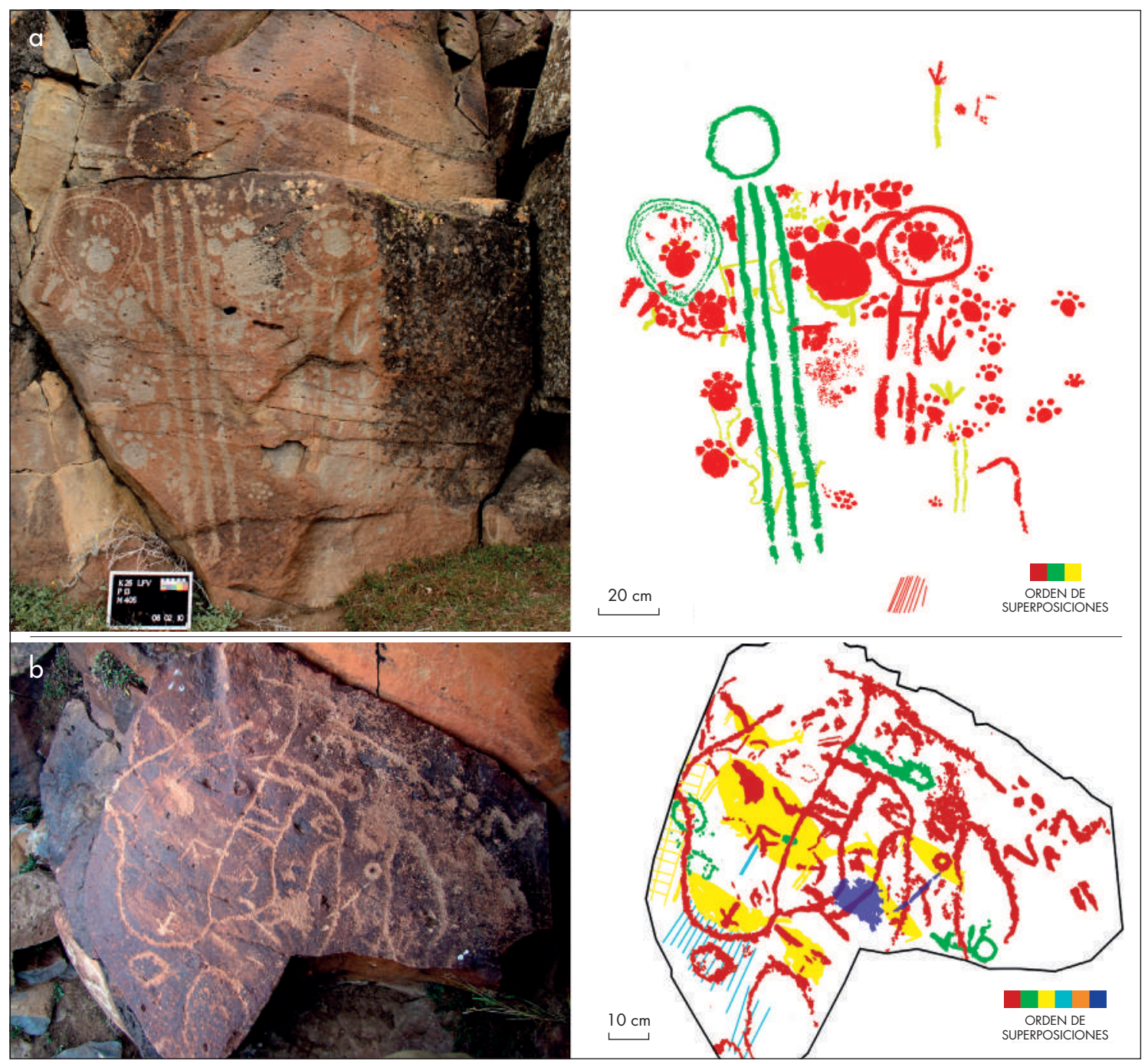

Figura 7. UT con alta densidad de motivos rupestres: a) sitio K25; b) sitio K27. A la izquierda la fotografía original y a la derecha el calco digital. En el borde inferior derecho de cada calco se puede observar una referencia con los colores utilizados para mostrar el orden de las superposiciones (los motivos superiores o no superpuestos se indican en bordó). Figure 7. Topographic Units with high density of rock art motifs: $\boldsymbol{a}$ ) site K25; $\boldsymbol{b}$ ) site K27. Original photo on the left, digital tracing on the right. Color key showing overlapping sequence on the lower right bottom of each tracing (higher or not overlapped motifs are shown in bordeaux).

\section{Variedad de información comunicada}

Los sitios de la muestra destacan por la gran variedad de tipos de motivos que presentan. Se registraron entre 24 (K185) y 30 (K25) de los 31 tipos definidos para la meseta (tabla 4) (Re 2010; Guichón 2018). ${ }^{7}$ Esta situación contrasta con el resto de los sitios del área en los cuales se observaron 21 tipos o menos (Guichón 2018; Re et al. 2019). En cuanto a los grupos de diseño (GD), se han identificado entre 29 (K27) y 38 (K25 y
K145) de los 40 propuestos (Re 2010; Re \& Guichón 2016). Como se planteó en trabajos anteriores (Re 2010), la mayor diversidad morfológica puede ser parcialmente explicada por el tamaño de la muestra. Sin embargo, como lo demuestran sitios de áreas cercanas, como la cuenca del lago Cardiel (Guichón 2018), también las poblaciones humanas del pasado pudieron potencialmente elegir representar de forma redundante un mismo tipo de motivo. Esto remarca la necesidad de no asumir a priori que la variabilidad 

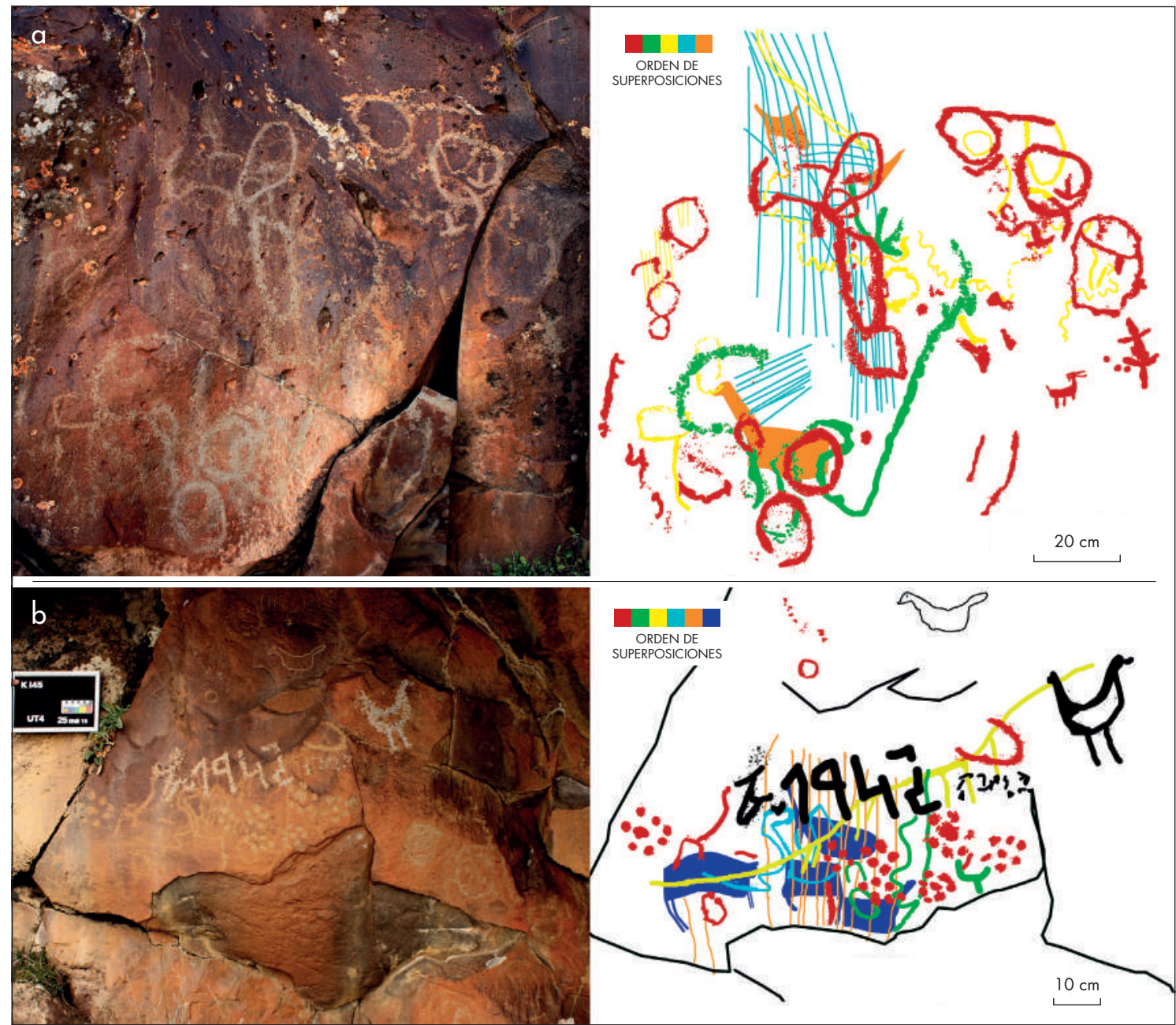

Figura 8. UT con alta densidad de motivos rupestres: a) sitio K26; b) sitio K145. A la izquierda la fotografía original y a la derecha el calco digital. En el borde superior izquierdo de cada calco se puede observar una referencia con los colores utilizados para mostrar el orden de las superposiciones (los motivos superiores o no superpuestos se indican en bordó). Figure 8. Topographic Units with high density of rock art: $\boldsymbol{a}$ ) site K26; $\boldsymbol{b}$ ) site K145. Original photo on the left, digital tracing on the right. Color key showing overlapping sequence on the upper left edge of each tracing (higher or not overlapped motifs are shown in bordeaux).

de las manifestaciones rupestres estaría dictada por el tamaño de los sitios.

En términos generales, se observa que los sitios comparten muchos de los tipos de motivos en porcentajes similares (tabla 4). Así, en frecuencias superiores al 10\% se hallan círculos, trazos y líneas rectas; mientras que en un rango de $2,5 \%$ a $10 \%$ se encuentran semicírculos, líneas sinuosas, curvas y quebradas, punteados, caóticos, huellas de felino y huellas humanas (figs. 7-10). Cabe destacar algunas diferencias en cuanto a las mayores frecuencias de representación de ciertos motivos. Así, resaltan guanacos y reticulados en K26 y K27, tridígitos en K25 y K145, punteados en K127 y K145 y huellas de felino en K25, K127 y K145. Los motivos hallados en porcentajes inferiores al 2,5\% presentan un comportamiento similar, donde resalta K25 por registrar figuras humanas (fig. $11 \mathrm{~m}$ ), figuras y huellas de caballo (fig. 11h) y piches (fig. 11b). En los sitios de la mitad sur se reconocen motivos de bandas, ${ }^{8}$ poco comunes en la meseta (fig. 11j).

Independientemente de la tipología, cada uno de estos sitios presenta motivos en muy baja frecuencia que llaman la atención debido a su morfología y dimensiones (figs. 7, 9a y b, y 11). Respecto de la morfología destacan 

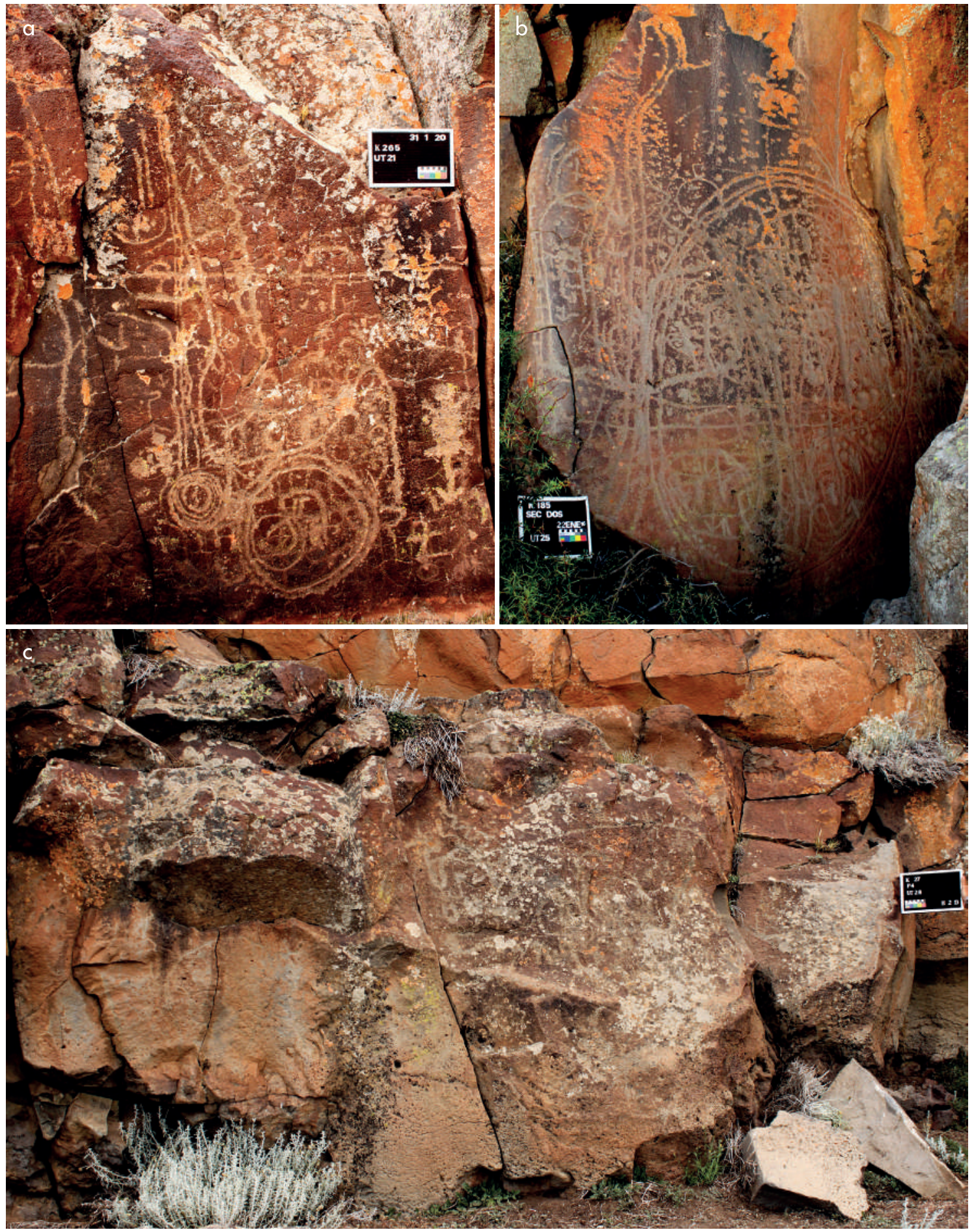

Figura 9. ut con alta densidad de motivos rupestres: a) sitio K265; b) sitio K185; c) sitio K127. Figure 9. Topographic Units with high density of rock art motifs: $\boldsymbol{a}$ ) site $\mathrm{K} 265 ; \boldsymbol{b})$ site $\mathrm{K} 185 ; \boldsymbol{c}$ ) site K127. 
Tabla 4. Categorías y tipos de motivos en los sitios bajo estudio (sin indeterminados). Referencias: X: Presencia, ${ }^{\star}$ Datos preliminares. Table 4. Categories and types of motifs in the sites under study (without indeterminate motifs). References: X: Presence, ${ }^{*}$ Preliminary data.

\begin{tabular}{|c|c|c|c|c|c|c|c|c|}
\hline & & \multicolumn{3}{|c|}{ SECTOR NORTE } & \multicolumn{4}{|c|}{ SECTOR SUR } \\
\hline & & K25 & K127 & K145 & K26 & K27 & K185-S2 & K265 \\
\hline \multicolumn{2}{|c|}{ Tipos de motivos } & $\%$ & $\%$ & $\%$ & $\%$ & $\%$ & $\%$ & $\%$ \\
\hline \multirow{17}{*}{ Abstractos } & Banda & - & - & - & 0,10 & 0,15 & $\mathrm{X}$ & $\mathrm{X}$ \\
\hline & Caóticos & 4,45 & 6,12 & 2,42 & 9,77 & 7,90 & $\mathrm{X}$ & $\mathrm{X}$ \\
\hline & Círculo & 13,34 & 10,87 & 13,71 & 20,37 & 12,97 & $\mathrm{X}$ & $\mathrm{X}$ \\
\hline & Cruz & 0,82 & 0,64 & 0,20 & 0,73 & 0,60 & $\mathrm{X}$ & $\mathrm{X}$ \\
\hline & Espiral & 0,18 & 0,24 & 0,30 & 0,62 & 0,89 & $\mathrm{X}$ & $\mathrm{X}$ \\
\hline & Geométrico complejo & 1,63 & 0,40 & 0,71 & 0,52 & 1,94 & $\mathrm{X}$ & $\mathrm{X}$ \\
\hline & Línea curva & 4,17 & 7,57 & 7,36 & 3,12 & 5,22 & $\mathrm{X}$ & $\mathrm{X}$ \\
\hline & Línea quebrada & 3,54 & 4,67 & 3,33 & 3,22 & 4,62 & $\mathrm{X}$ & $\mathrm{X}$ \\
\hline & Línea recta & 10,80 & 14,49 & 9,27 & 11,95 & 14,01 & $\mathrm{X}$ & $\mathrm{X}$ \\
\hline & Línea sinuosa & 6,26 & 2,74 & 5,34 & 4,16 & 4,17 & $\mathrm{X}$ & $\mathrm{X}$ \\
\hline & Punteados & 5,90 & 11,51 & 10,79 & 2,70 & 5,37 & $\mathrm{X}$ & $\mathrm{X}$ \\
\hline & Radial & 1,91 & 0,40 & 1,11 & 0,10 & 0,75 & $\mathrm{X}$ & $\mathrm{X}$ \\
\hline & Reticulado & 0,36 & 0,40 & 0,30 & 3,85 & 3,73 & $\mathrm{X}$ & $\mathrm{X}$ \\
\hline & Semicírculo & 10,07 & 6,36 & 4,33 & 6,55 & 4,62 & $\mathrm{X}$ & $\mathrm{X}$ \\
\hline & Subcircular & 2,36 & 1,21 & 0,91 & 2,60 & 2,24 & $\mathrm{X}$ & $\mathrm{X}$ \\
\hline & Trazo & 12,34 & 14,33 & 11,59 & 10,60 & 13,11 & $\mathrm{X}$ & $\mathrm{X}$ \\
\hline & Otros abstractos & 1,45 & 0,97 & 1,01 & 0,73 & 1,94 & $\mathrm{X}$ & $\mathrm{X}$ \\
\hline \multirow{10}{*}{ Zoomorfos } & Caballo & 0,09 & - & - & - & - & - & - \\
\hline & Escena & 0,09 & 0,24 & 0,71 & 0,21 & 0,15 & - & - \\
\hline & Guanaco & 1,18 & 0,81 & 2,12 & 8,63 & 9,54 & $\mathrm{X}$ & $\mathrm{X}$ \\
\hline & Huella de caballo & 0,27 & - & - & - & - & - & - \\
\hline & Huella de felino & 7,53 & 7,41 & 11,90 & 1,46 & 3,13 & $\mathrm{X}$ & $\mathrm{X}$ \\
\hline & Huella de guanaco & 0,54 & - & - & 0,21 & 0,45 & $\mathrm{X}$ & $\mathrm{X}$ \\
\hline & Matuasto & 1,63 & 1,05 & 0,71 & 1,87 & 0,75 & $\mathrm{X}$ & $\mathrm{X}$ \\
\hline & Piche & 0,18 & - & - & - & - & - & - \\
\hline & Tridígito & 5,26 & 2,58 & 4,94 & 1,98 & 1,64 & $\mathrm{X}$ & $\mathrm{X}$ \\
\hline & Zoomorfo indeterminado & 0,09 & 0,48 & 0,10 & 0,21 & - & - & - \\
\hline \multirow{3}{*}{ Antropomorfos } & Figura humana & 0,73 & - & - & - & - & - & $\mathrm{X}$ \\
\hline & Huella humana & 2,72 & 4,43 & 5,95 & 3,64 & 0,15 & $\mathrm{X}$ & $\mathrm{X}$ \\
\hline & Mano & 0,09 & 0,08 & 0,91 & 0,10 & - & $\mathrm{X}$ & $\mathrm{X}$ \\
\hline \multicolumn{2}{|l|}{ Total \% } & 100 & 100 & 100 & 100 & 100 & & \\
\hline \multicolumn{2}{|l|}{ Total $n .^{\circ}$} & 1102 & 1242 & 992 & 962 & 671 & $+500^{*}$ & $+1000^{*}$ \\
\hline
\end{tabular}



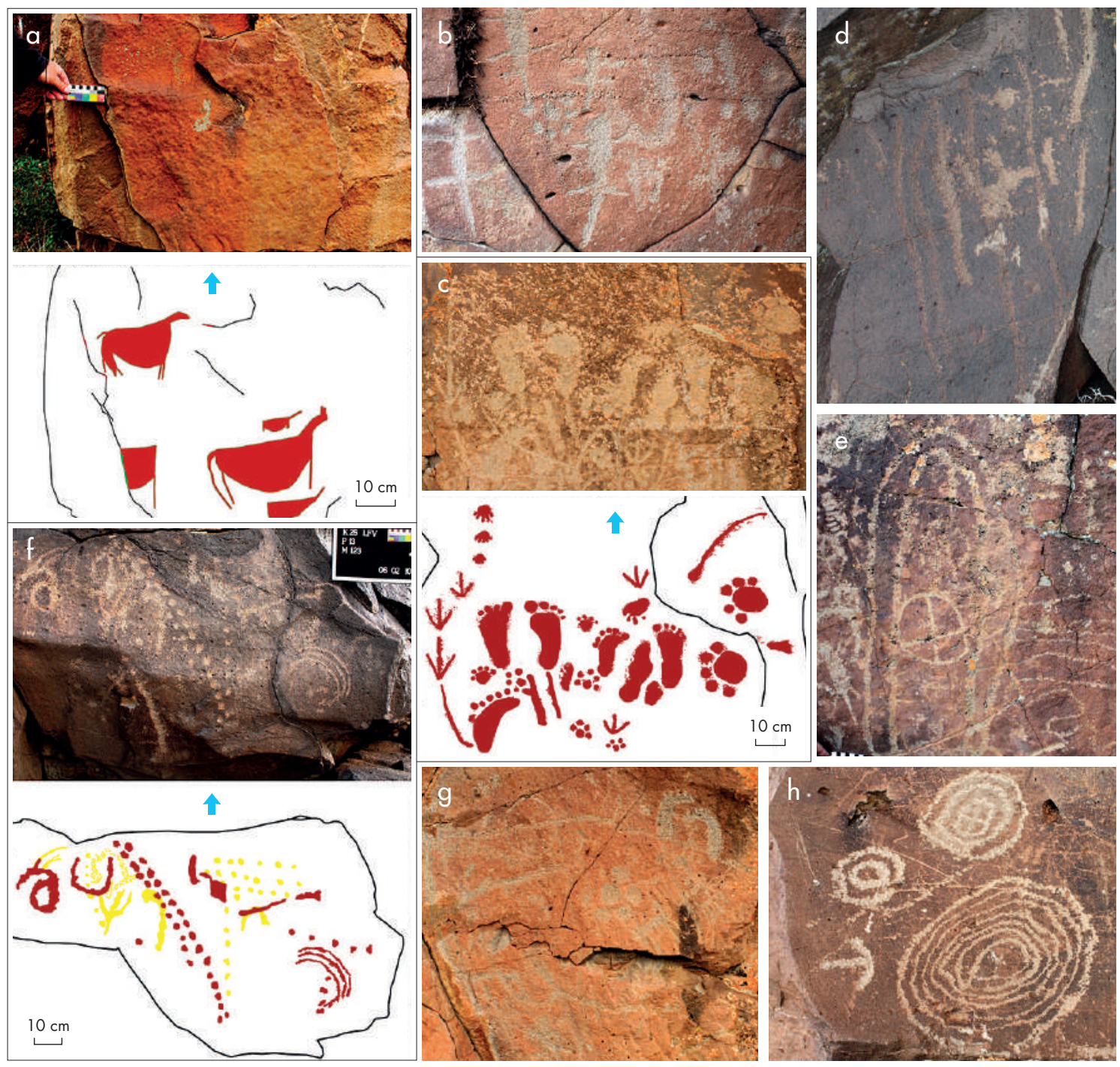

Figura 10. Tipos de motivos representados en mayor frecuencia: a) guanaco GD1, sitio K145; b) matuastos y huella de felino, sitio K25; c) huellas humanas, tridígitos, huellas de felino y líneas curvas, sitio K145; d) líneas rectas, trazos y punto, sitio K25; e) círculo y línea sinuosa, sitio K185; f) punteados, semicírculos, círculo y línea recta, sitio K25; g) huellas humanas y de felino, líneas rectas, círculo y guanaco GD2, sitio K127; h) círculos y tridígitos, sitio K27. Figure 10. Most frequent motif types: a) guanaco GD1, site 145; b) lizards and feline footprints, site K25; c) human footprints, bird footprints, feline footprints, and curved lines, site K145; d) straight lines, traces, and point, site K25; e) circle and winding line, site K185; $f$ ) dotted lines, semicircles, circles, and straight lines, site K25; $g$ ) human and feline footprints, straight lines, circle, and guanaco GD2, site K127; h) circles and bird footprints, site K27.

escenas de caza con pisadas humanas (K26, K127, K145 y K185), con figura humana (K127) (fig. 11i), con posibles huellas de huemul (K27 y K145) (fig. 11g) y una escena de cópula de guanacos (K27). También se observan abstractos y, en particular, geométricos complejos de gran variedad en todos los sitios (figs. 7b, 9a y b, 11a, $\mathrm{e}, \mathrm{f}, \mathrm{j}, \mathrm{k}, \mathrm{l})$. En cuanto a las dimensiones, hay motivos de gran tamaño $\left(>500 \mathrm{~cm}^{2}\right)$ como huellas de felino (K25,
K145 y K185), círculos y óvalos con líneas asociadas (K25, K185 y K265), entre otros (figs. 7, 9a y b, 11a y k).

Entre las técnicas de ejecución predomina el grabado. La variante de picado ha sido utilizada para representar más del 70\% de los motivos de cada sitio (figs. 7-11). También se registraron motivos incisos y raspados cuya frecuencia oscila entre $4 \%$ y $14 \%$ y combinación de ellos en proporciones aun menores (figs. 10a y 11j). Si 

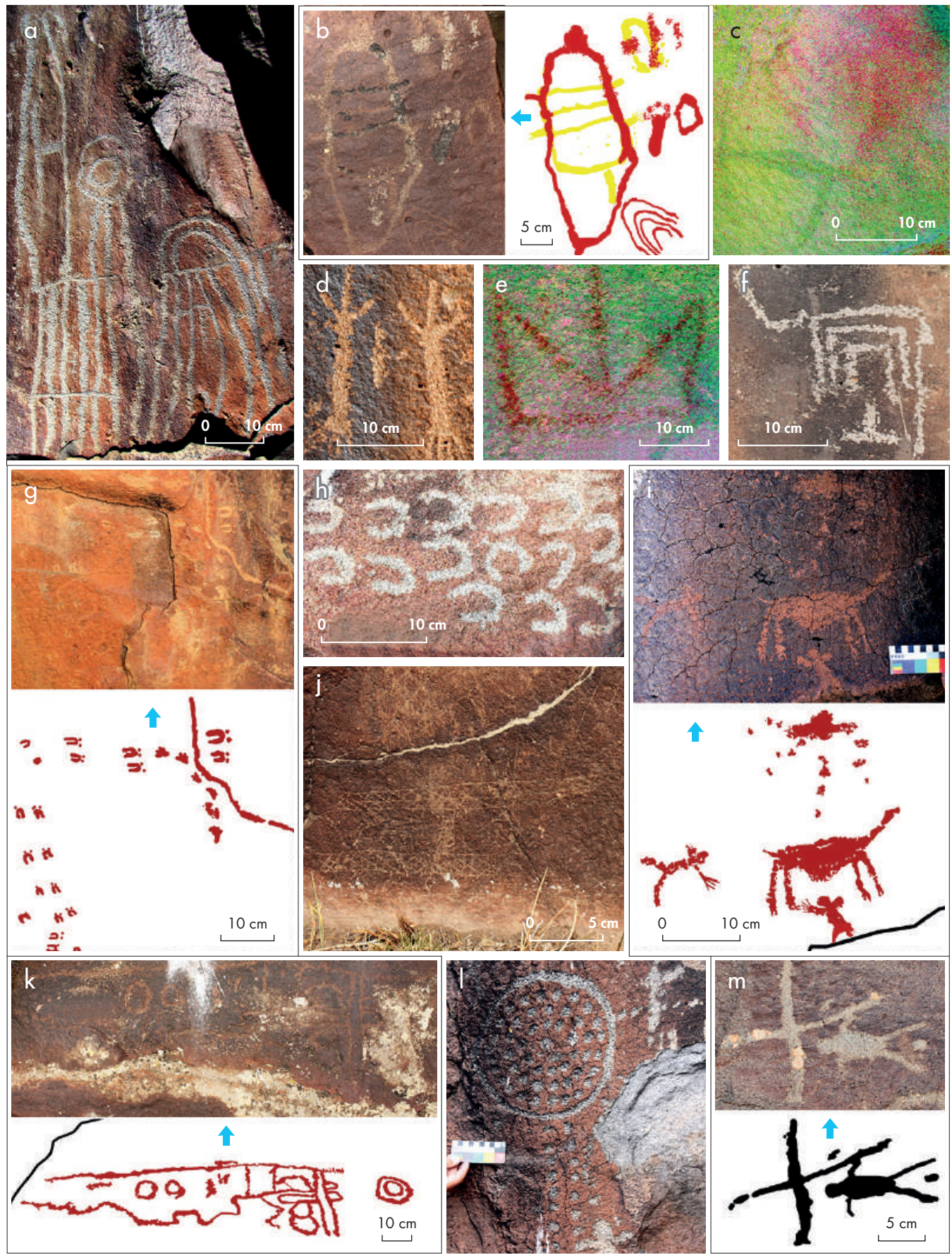

Figura 11. Tipos de motivos y diseños poco frecuentes o de grandes dimensiones: a) K27 geométrico complejo; b) K127, piche; c) K185, negativo de mano; d) K127, geométrico complejo; e) K185, triángulo (otros abstractos);f) K27, geométrico complejo; g) K145, escena de caza (representada mediante pisadas); h) K25, pisadas de caballo; i) K127, escena de caza con figura humana; j) K265, banda; k) K25, geométrico complejo; 1) K145, círculo con punteado asociado; m) K25, figura humana con cruz. Figure 11. Types of motifs and rare or large designs: a) K27, complex geometrical design; b) K127, piche; c) K185, hand stencil; d) K127, complex geometrical design; $\boldsymbol{e}$ ) K185, triangle (other abstract designs); f) K27, complex geometrical design; $g$ ) K145, hunting scene (represented through footprints); $h$ ) K25, horse footprints; $i)$ K127, hunting scene with human figure; j) K265, band; $k$ ) K25, complex geometrical design; l) K145, circle with dots associated; $m$ ) K25, human figure with cross. 
Tabla 5. Grados de pátinas y cantidad de superposiciones en los sitios bajo estudio. Referencias: X: Presencia. Table 5. Degrees of patinas and amount of superpositions in the sites under study. References: X: Presence.

\begin{tabular}{|c|c|c|c|c|c|c|c|c|c|c|c|c|c|}
\hline & & \multicolumn{6}{|c|}{ SECTOR NORTE } & \multicolumn{6}{|c|}{ SECTOR SUR } \\
\hline & & \multicolumn{2}{|c|}{ K25 } & \multicolumn{2}{|c|}{ K127 } & \multicolumn{2}{|c|}{ K145 } & \multicolumn{2}{|c|}{ K26 } & \multicolumn{2}{|c|}{ K27 } & \multirow{2}{*}{$\begin{array}{c}\text { K185-S2 } \\
\text { N }\end{array}$} & \multirow{2}{*}{$\begin{array}{r}\mathrm{K} 265 \\
\mathrm{~N}\end{array}$} \\
\hline & & $\mathrm{N}$ & $\%$ & $\mathrm{~N}$ & $\%$ & $\mathrm{~N}$ & $\%$ & $\mathrm{~N}$ & $\%$ & $\mathrm{~N}$ & $\%$ & & \\
\hline \multirow{3}{*}{ Pátina } & 3 (clara) & 591 & 53 & 610 & 62 & 634 & 66 & 566 & 63 & 432 & 63 & $\mathrm{X}$ & $\mathrm{X}$ \\
\hline & 2 (intermedia) & 379 & 34 & 268 & 29 & 263 & 28 & 270 & 22 & 153 & 22 & $\mathrm{X}$ & $\mathrm{X}$ \\
\hline & 1 (oscura) & 151 & 13 & 86 & 9 & 62 & 6 & 126 & 15 & 104 & 15 & $\mathrm{X}$ & $\mathrm{X}$ \\
\hline \multicolumn{2}{|c|}{$\mathrm{N}$ superposiciones } & \multicolumn{2}{|c|}{238} & \multicolumn{2}{|c|}{160} & \multicolumn{2}{|c|}{160} & \multicolumn{2}{|c|}{245} & \multicolumn{2}{|c|}{262} & $\mathrm{X}$ & $\mathrm{X}$ \\
\hline
\end{tabular}

bien este patrón es compartido por casi todos los sitios analizados, destaca la mayor frecuencia relativa de las técnicas de inciso, raspado y raspado-inciso en K26 y K27. También se ha registrado en baja frecuencia pintura en K127, K145, K185 y K265, la que fue aplicada mediante estarcido para realizar negativos de manos (fig. 11c), aunque también se identificaron motivos ejecutados por medio de aplicación directa (fig. 11e). Estas representaciones fueron realizadas en tonos rojo, blanco y un posible ocre.

\section{Lapsos temporales representados}

En los cinco sitios analizados sistemáticamente, en primera instancia, se registró la presencia de los tres grados de pátina con un patrón de frecuencias relativas muy similar (tabla 5). ${ }^{9}$ En todos domina la pátina clara (grado 3 ) con porcentajes mayores al 50\%, seguida por la intermedia (20\% a $30 \%$ ) y luego la oscura (menos de 15\%) (fig. 12). Solo se observan diferencias relacionadas con una frecuencia levemente mayor de esta última en K25, K26 y K27. Asimismo, todos los sitios presentan gran cantidad de superposiciones que superan los 160 casos (tabla 5, figs. 7, 8 y 9). Con mayor número se registra K27 $(\mathrm{N}=262)$, luego $\mathrm{K} 26(\mathrm{~N}=245)$ y K25 $(\mathrm{N}=$ 238). Aún los sitios con un análisis preliminar (K185 y K265) exhiben gran cantidad de superposiciones ilustradas en paneles colmados de motivos.

Con respecto a la secuencia de ejecución de los distintos tipos de motivos y técnicas que ha sido propuesta para la meseta del Strobel, cabe mencionar que las representaciones rupestres de los sitios K25, K26 y K27 fueron fundamentales en el armado original de esta secuencia (Re 2010; Guichón et al. 2016; Guichón 2018) (ver Antecedentes). El análisis de K127 y K145 evidencia una gran coherencia con la secuencia de ejecución, la cual se corrobora también, pero de manera preliminar, en K185 y K265. Por lo tanto, puede postularse que, en los siete sitios analizados, se realizaron manifestaciones rupestres desde ca. 5000 años AP hasta momentos de contacto, es decir, a lo largo de toda la tendencia temporal establecida para la meseta.

No obstante, existen algunas diferencias entre los sitios K25, K26 y K27, ya que cuentan con una mayor frecuencia relativa de grabados pátina 1 y de superposiciones. A esto se le agrega la mayor cantidad, en K26 y K27, de motivos diagnósticos vinculados al Holoceno Medio, como guanacos GD1 y reticulados. Estos datos sugieren espacios utilizados con mayor intensidad durante los primeros momentos de la secuencia que contrasta con una menor relevancia respecto del resto de los sitios durante ese período.

Posteriormente, a partir de 2500 años AP y principalmente los últimos 1000 años, se plantea que todos los sitios tuvieron una gran importancia en la ejecución de motivos rupestres. Más del $80 \%$ de las representaciones, incluso en K26 y K27, es asignado a este período. Estas afirmaciones se sostienen en los datos provistos por las pátinas, las superposiciones y la presencia de motivos diagnósticos (bandas, huellas de felino y humanas, matuastos, escenas, guanacos GD2, entre otros), en conjunto con la información contextual como fechados y otras líneas de evidencia. ${ }^{10}$ Es posible que durante momentos de contacto (siglos XVI y XVII) se haya continuado la producción de motivos en los sitios, sin embargo, K25 es el único que cuenta con referentes novedosos como figuras de caballo, sus huellas y una figura humana con cruz (Re et al. 2010a) (fig. 11h y m). 

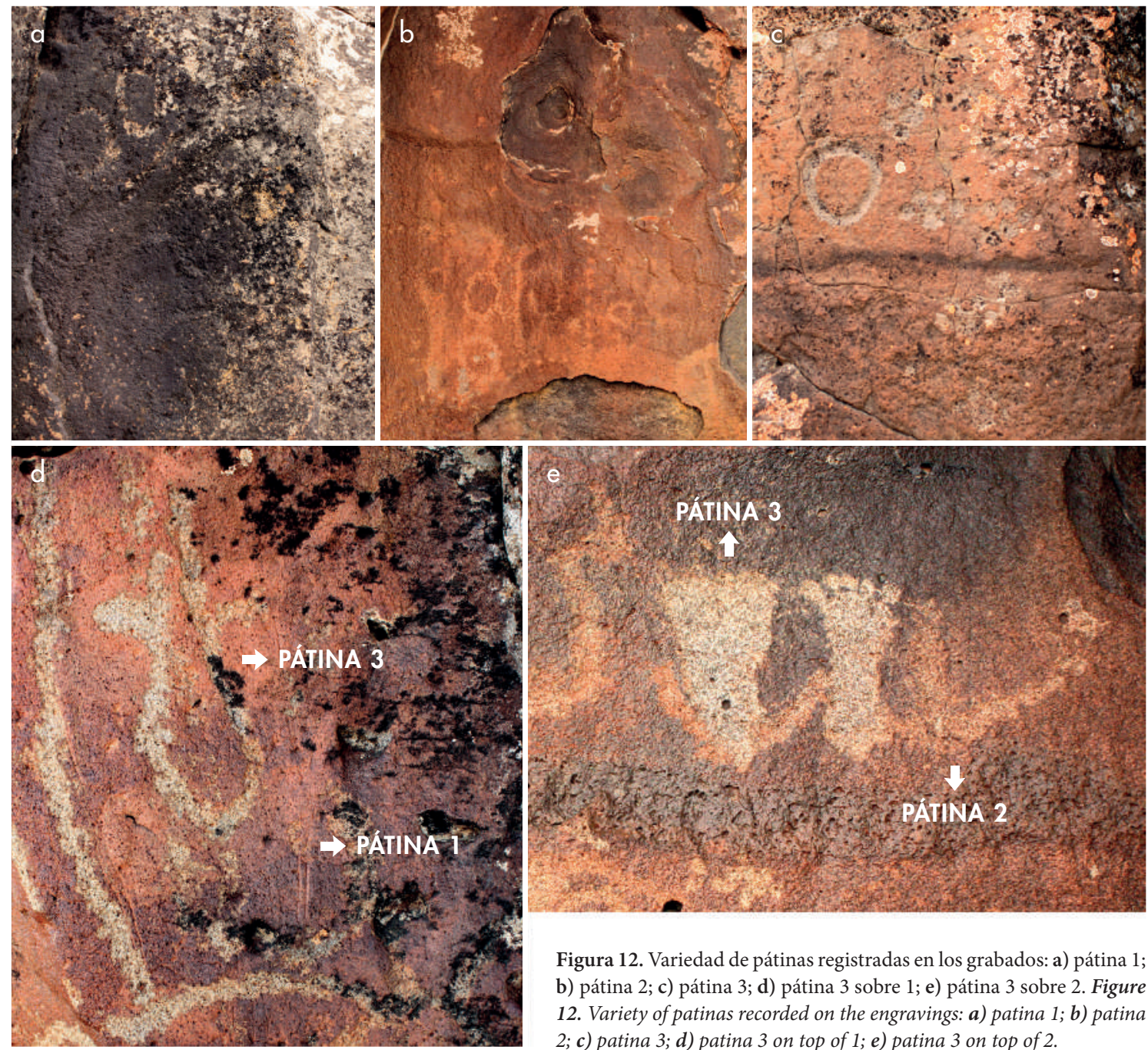

Figura 12. Variedad de pátinas registradas en los grabados: a) pátina 1; b) pátina 2; c) pátina $3 ;$ d) pátina 3 sobre 1; e) pátina 3 sobre 2. Figure 12. Variety of patinas recorded on the engravings: $\boldsymbol{a}$ ) patina $1 ; \boldsymbol{b}$ ) patina 2 ; c) patina $3 ; d$ ) patina 3 on top of $1 ; e)$ patina 3 on top of 2 .

Los sitios aquí considerados parecen presentar frecuencias bajas de motivos (menos de 100) asociadas al Holoceno Medio. Destaca que, aun descontando estas representaciones, todos ellos registran más de 500 motivos rupestres. Esta discriminación permite sugerir que la alta concentración de manifestaciones no se debió solamente a la acumulación de motivos desde los primeros momentos de ocupación de la meseta. Por el contrario, se correspondería mayoritariamente con un período puntual de uso de la meseta vinculado a los últimos 2500 años.

\section{DISCUSIÓN}

Como quedó previamente demostrado, la comunicación por medios materiales en la meseta del Strobel no fue homogénea, sino que, por el contrario, algunos espacios fueron privilegiados. Por lo tanto, para comprender mejor las estrategias desplegadas por las poblaciones cazadoras-recolectoras, se propuso profundizar en los "puntos claves" de la comunicación, en un sentido espacial, mediante la discusión de distintos ejes. Para abordar la problemática se seleccionaron aquellos sitios con más de 500 motivos rupestres. El análisis desarrollado permitió constatar que en todos ellos se dio, además de 
una intensa producción rupestre, una gran diversidad en los motivos ejecutados, asignados en su mayoría a los últimos 2500 años. Por lo tanto, sobre la base de los datos presentados y la perspectiva teórica asumida, se infiere que en estos sitios se comunicó una variedad de información muy amplia en un período temporal acotado. Además, se identificaron tanto factores comunes como divergencias entre ellos.

El abordaje de los lapsos temporales representados permitió evidenciar la presencia de varios momentos de ejecución con similar cronología relativa en todos los sitios. La mayor cantidad de guanacos GD1, reticulados y motivos con pátinas oscuras, permite plantear que K26 y K27, y en menor medida K25, tuvieron una mayor importancia en los circuitos de comunicación durante el Holoceno Medio. Asimismo, durante el Holoceno Tardío, y en particular en los últimos 1000 años, se sugiere que todos los sitios analizados tuvieron un uso intenso y de similar jerarquía. De esta manera, se propone que su uso fue relativamente contemporáneo durante este lapso.

En cuanto a los emplazamientos seleccionados, se observó que los sitios se registran en diversas situaciones topográficas y ampliamente distribuidos en la meseta, tanto en diferentes sectores como en distintos rangos altitudinales. Si bien hay una mayor cantidad en el centro y oeste a más de $900 \mathrm{msnm}$, no se evidencia una clara jerarquización de este sector. Esto complejiza el panorama que había sido descripto mediante el análisis de sitios de la porción norte de la meseta, en el cual se reconocía otro patrón de distribución de los espacios jerarquizados (Re et al. 2019) (ver Antecedentes).

En términos de los posibles criterios empleados para la selección de estos espacios, destacan ciertas características compartidas. En primer lugar, la proximidad a una fuente de agua, ya que la mayoría de los sitios se encuentra a menos de 50 metros de este recurso, aunque la estabilidad de estas fuentes puede ser media o alta. En segundo lugar, en todos los sitios se constata la presencia de un excelente reparo de los vientos provenientes del oeste, dado por paredones altos de extensión igual o mayor a $100 \mathrm{~m}$ y una amplia área plana colindante. Esto último indica la selección de espacios aptos para grupos numerosos de individuos. Destaca la ausencia de rasgos del paisaje que faciliten la identificación de estos lugares a grandes distancias. De esta manera, el uso reiterado de los mismos sugiere el conocimiento previo del paisaje y una transmisión de su ubicación entre los grupos humanos que usaron esta meseta, ya que presentan una baja visibilidad.

Las restantes líneas de evidencia (tecnología lítica, estructuras de piedra y restos faunísticos) siguen sosteniendo en términos generales el uso logístico o estacional de la meseta del Strobel en su conjunto (Goñi et al. 2014; Re et al. 2017; Flores Coni 2018). No obstante, recientemente se ha demostrado también variedad en las actividades realizadas en su interior (Flores Coni 2018), así como la potencial participación de todo el grupo familiar en lugares puntuales (Guichón \& Re 2020). En ese marco, el emplazamiento de los puntos claves indica una estrategia de comunicación donde se privilegiaron espacios que pueden reunir grupos más numerosos de personas y donde la ejecución de los motivos estuvo acompañada de rangos diversos de actividades (Flores Coni 2018).

Con respecto a la intensidad de producción rupestre, variables como cantidad de motivos y UT apuntan a la gran importancia para la comunicación de todos los sitios analizados. Aunque en algunos se eligió concentrar la información almacenada en una extensión menor de soporte, en otros se encuentra más extendida, y todos tienen en su interior sectores densamente utilizados para la ejecución de representaciones. En términos generales, se evidencia una estrategia dominante tendiente a acumular información en ciertos espacios por medio de las manifestaciones, más allá de la disponibilidad del soporte.

Por último, en cuanto a la variedad de información comunicada, se evidencia una gran diversidad de motivos, diseños, técnicas y tamaños representados en los sitios, lo que podría estar indicando una multiplicidad de tipos de información transmitida, incluyendo aspectos ecológicos, económicos, sociales e ideológicos. Además, dado que esa variedad circula entre todos estos espacios al menos durante el Holoceno Tardío, se refuerza la propuesta de un uso relativamente contemporáneo de los sitios en los circuitos de comunicación.

También se registraron diferencias en la frecuencia de representación de algunos motivos. Algunos casos como los guanacos y reticulados se considera que responden a diferencias cronológicas. Ahora bien, incluso restringiéndose a aquellos motivos asignados al Holoceno Tardío, se identificaron variaciones. Así, por un lado, la mayor cantidad relativa de algunos tipos de motivos más comunes (p. e., punteados, huellas humanas y huellas de felino en K127 y K145) podría responder a la mayor importancia de ciertos sitios para la transmisión 


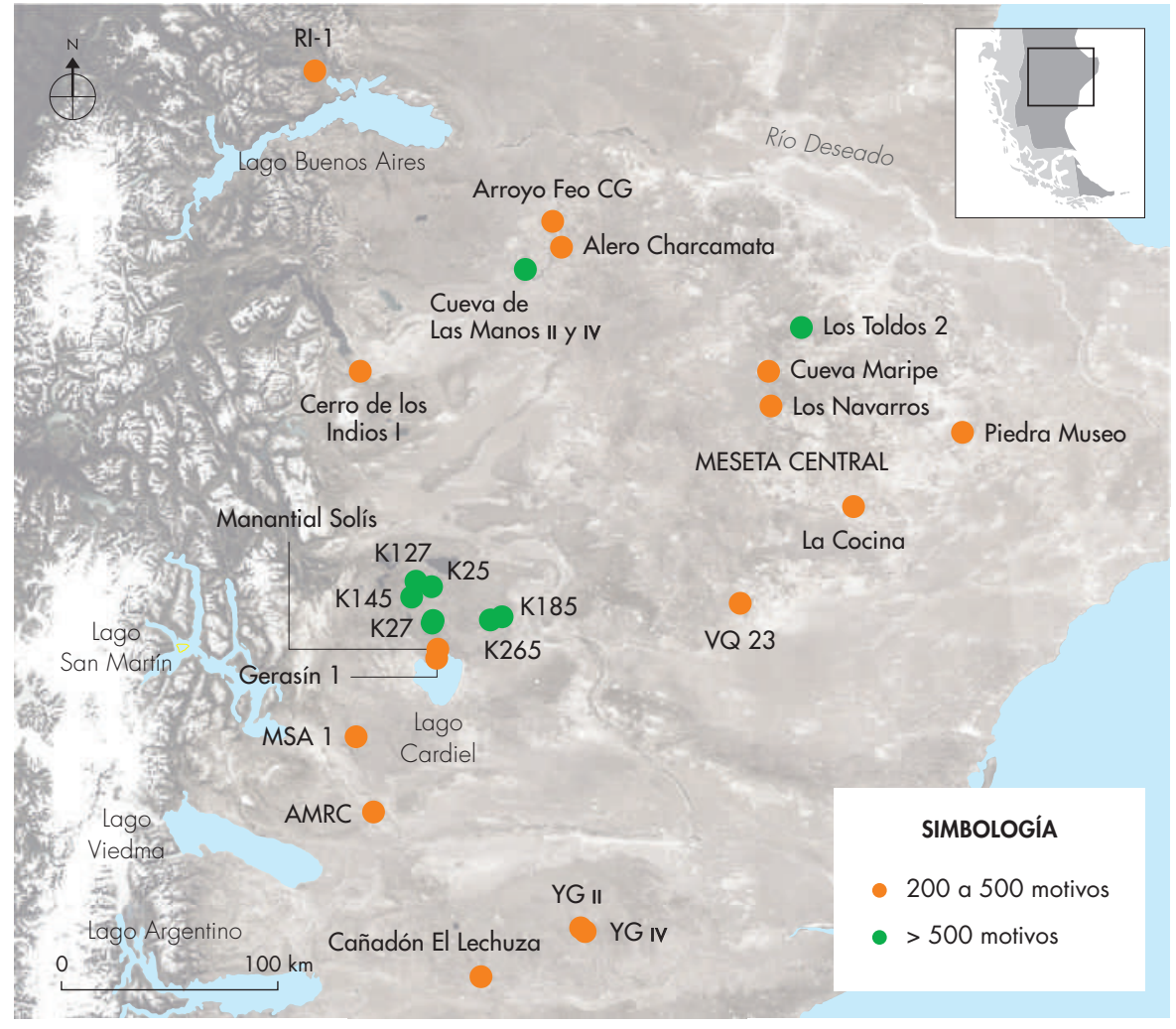

Figura 13. Ubicación de sitios con más de 200 motivos rupestres y asignación de parte del repertorio al Holoceno Tardío en la Patagonia meridional. Figure 13. Location of sites with more than 200 rock art motifs and with part of the repertoire assigned to the Late Holocene in southern Patagonia. de ciertos mensajes, por sobre los tipos de información previamente referidos. Por otro lado, la identificación de divergencias relacionadas con motivos de diseños únicos o poco frecuentes podría reflejar situaciones más particulares, tales como identidades individuales.

Los ejes seleccionados para abordar los puntos claves de la comunicación en la meseta del Strobel apuntan a su uso intenso y reiterado, así como a la posible participación de una mayor cantidad de individuos en la producción o el uso de las representaciones rupestres en comparación con los restantes sitios de esta área. Todo ello permitiría sostener la programación del uso de estos espacios en el marco de circuitos de comunicación establecidos por las poblaciones cazadoras-recolectoras, que implicarían escalas espaciales más amplias.

Considerando toda la información en su conjunto, tanto aquella que proviene del análisis realizado como de las otras líneas de evidencia, cabe reflexionar sobre diferentes escenarios posibles en los que se podría haber dado este uso relativamente contemporáneo para la ejecución de motivos rupestres de los sitios analizados. En primer lugar, dada su ubicación en distintos sectores de la meseta con diferentes características ambientales y climáticas, puede plantearse como hipótesis su uso complementario en distintos momentos de la primavera y del verano por parte de los mismos grupos humanos en función de los recursos disponibles. Otra alternativa, no excluyente, refiere al uso tanto simultáneo como diferido por parte de grupos que comparten códigos visuales (p. e., Acevedo \& Fiore 2020), aunque provenientes de distintas regiones y que podrían haber utilizado diversas vías de acceso a la meseta. Ambos escenarios son coherentes tanto con el uso logístico y estacional de este espacio como con la convergencia poblacional propuesta para momentos tardíos.

Para evaluar la relevancia de los sitios bajo estudio y de la meseta del Strobel en general en una escala espacial amplia, se hace necesario contextualizar con la información publicada en otras regiones de la Patagonia meridional, más allá de los sesgos que puedan existir (p. e., intensidad de las investigaciones) (fig. 13). Por un lado, cabe considerar otros espacios estudiados y abordados con los mismos criterios metodológicos por miembros del mismo equipo de investigación en 
el centro-oeste de Santa Cruz. Así, se observa que en la región comprendida entre la meseta del lago Guitarra al norte y la cuenca de los lagos Tar y San Martín al sur no se registran otros sitios con más de 500 motivos (Re 2010; Guichón 2018, entre otros). Se detectaron solo cuatro sitios con más de 200 motivos (fig. 13): Manantial Solís y Gerasín 1 en la cuenca del lago Cardiel (Guichón 2018), MSA1 en las mesetas San Adolfo y Cardiel Chico (Re et al. 2013-2014) ${ }^{11}$ y AMRC en la cuenca de los lagos Tar y San Martín (Re \& Belardi 2019). Si bien se evidencia una mayor cantidad de pinturas en las cuencas lacustres en contraposición al dominio de los grabados en las mesetas, gran parte de la producción rupestre de estas regiones fue asignada a los últimos 2500 años y se ha sugerido que se trata de espacios utilizados de forma complementaria a lo largo del ciclo anual de las poblaciones cazadoras-recolectoras (Re 2010; Guichón 2018; Goñi et al. 2019; Re \& Belardi 2019, entre otros). Más allá de la cantidad de manifestaciones, las representaciones rupestres de estos sitios son los que presentan además una mayor diversidad morfológica.

Por otro lado, resulta de utilidad realizar una comparación sintética con otras regiones de la Patagonia meridional. En relación con los fines de este artículo, se considera el territorio comprendido entre el río Deseado al norte y el río Santa Cruz al sur y a aquellos sitios que presentan manifestaciones rupestres asignadas al Holoceno Tardío (fig. 13). De acuerdo con la información publicada, los únicos sitios que superan los 500 motivos son Cueva de las Manos, sitios ir y iv, en el Alto Río Pinturas (Gradin 1983) y la cueva 2 de Los Toldos (Carden \& Miotti 2020). Estos sitios fueron utilizados a lo largo de todo el Holoceno y se plantea una menor intensidad de producción durante momentos tardíos.

En otro aspecto, se registran 12 sitios que presentan entre 200 y 500 motivos. Entre ellos, se cuentan en primer lugar ocho cuevas y aleros, tales como Alero Charcamata y Cueva Grande del Arroyo Feo, Cerro de los Indios 1, Cueva Grande de Piedra Museo, Cueva Maripe, Viuda Quenzana 23, La Cocina y R-I 1 (Gradin 1983; Carden 2008; Artigas et al. 2016; Fiore \& Acevedo 2019; González Dubox et al. 2021). Para casi todos estos casos se ha planteado una mayor cantidad de ocupaciones durante el Holoceno Medio y un uso exclusivo o predominante de la pintura. Estos sitios presentan emplazamientos diferentes (más acotados y próximos a otras cuevas y aleros), por lo cual se debe ajustar la comparación. No obstante, aún si se restringe el análisis de los sitios presentados en este trabajo a las concentraciones con mayor cantidad de motivos, estas destacan por contar con más de 400 representaciones de diversos tipos.

Asimismo, se han documentado cuatro sitios/ localidades sobre paredones similares a los de la meseta del Strobel que presentan entre 200 y 500 motivos, como Los Navarros y Yaten Guajen II y, con más de $1 \mathrm{~km}$ de extensión, cañadón El Lechuza y Yaten Guajen III (Fiore \& Ocampo 2009; Blanco 2015; Fiore \& Acevedo 2016). A partir de diversos indicadores, algunos investigadores han sugerido que la mayoría de los motivos de estos sitios habrían sido ejecutados durante el Holoceno Tardío, aplicando mayormente la técnica del grabado.

Se entiende que toda la porción considerada de la Patagonia meridional estuvo vinculada durante el Holoceno Tardío con circuitos de circulación de información, bienes y personas (Goñi et al. 2019). Las diferencias detectadas en las manifestaciones rupestres de dicho período, en las distintas regiones se relacionarían con aspectos variados que incluirían, entre otros, las características del soporte, las actividades asociadas y una diferenciación social, sin llegar a una demarcación activa de territorios (Goñi et al. 2019).

Las tendencias bosquejadas a escala macrorregional permiten avanzar en la contextualización de los resultados alcanzados. Estas refuerzan la hipótesis de un cambio en los mecanismos empleados para la transmisión de información por medios materiales, donde reparos más abiertos, como paredones, cobran mayor relevancia durante momentos tardíos, en conjunto con el uso más frecuente de la técnica del grabado (ver citas en Goñi et al. 2019). Así, se hace aun más evidente la importancia de los sitios bajo análisis como puntos claves en los circuitos de comunicación de los grupos cazadores-recolectores durante los últimos 2500 años en la Patagonia meridional. Si bien quedan muchas interrogantes y variables por explorar, se espera que el análisis aquí realizado contribuya a una mayor comprensión de los mecanismos y las estrategias que estos grupos desarrollaron para llevar adelante la comunicación por medio de las representaciones rupestres.

Agradecimientos Agradecemos a los dueños y al personal de las estancias Las Tunas, La Paloma, Laguna Verde, Lago Strobel y La Justita y de Pto. La Nativa por su esencial e invalorable ayuda y amistad. A las autoridades locales de Gobernador Gregores y Perito Moreno, a la Asociación Identidad y a la empresa Goldcorp por su apoyo. Además, a los miembros del equipo de investigación 
que participaron en los relevamientos de campo. Un especial agradecimiento a los evaluadores por sus pertinentes comentarios. La investigación fue financiada por UBA (UВACYT 2018-2020 20020170100150BA), АNPCYT (Ріст2016-0373, РІСт2018-3813, РіСт2018-3336, РіСт2018-3344 у РіСт2019-1726) y el Ministerio de Cultura de la Nación (Argentina).

\section{NOTAS}

${ }^{1}$ Los grabados del siglo xx realizados por las nuevas poblaciones europeas y criollas no fueron considerados en este trabajo.

${ }^{2}$ Por problemas locales de preservación, se han registrado escasos restos faunísticos en mal estado de conservación en las excavaciones de los sitios analizados (Re et al. 2017). Por otra parte, solo se han detectado escasos tiestos cerámicos en tres sitios de toda la meseta del Strobel (K28, K205 y K268), que no incluyen a los aquí estudiados (Flores Coni 2018 y datos propios inéditos).

${ }^{3} \mathrm{Si}$ bien es posible que también se hayan utilizado otros medios materiales de comunicación como cueros o pinturas corporales, estos no se han preservado en el registro arqueológico de Patagonia meridional.

${ }^{4}$ Las unidades topográficas (UT) son segmentos del soporte diferenciados a partir de características microtopográficas de la roca como orientación, inclinación y presencia de fracturas (Re 2010).

${ }^{5}$ K185-La Paloma es una localidad que cuenta con varios sectores distanciados entre sí. Aquí se toma el Sector 2 (S2), por su mayor cantidad de motivos.

${ }^{6} \mathrm{Si}$ bien en trabajos anteriores se ha presentado como una localidad con más de 500 motivos, K22-El Lobo no fue considerada en esta ocasión ya que reúne varios sectores distanciados a lo largo de $1 \mathrm{~km}$ (Re et al. 2010b), por lo que no es comparable con el resto de los sitios seleccionados.

${ }^{7}$ El único tipo de motivo ausente en los sitios analizados es el de "ave". Este fue identificado en un único sitio de la meseta (K147) (Re et al. 2019).

${ }^{8}$ Las bandas están compuestas por dos líneas paralelas rellenas con tramas en zigzag, líneas cortas que unen las líneas principales, líneas oblicuas, entre otras (Guichón 2018).

${ }^{9}$ Las pátinas son el resultado de numerosos factores, incluyendo el tiempo transcurrido, la orientación de las UT, el tipo de roca, los líquenes, entre otros (ver discusión resumida en Re 2010). No obstante, tomadas en conjunto con otros indicadores, se considera que son un elemento más para estimar la cronología relativa de los motivos.

${ }^{10}$ Se obtuvieron seis fechados de las excavaciones en K25, K26, K27 y K127 que indican ocupaciones al menos entre 1200 años AP y la actualidad (Re et al. 2017; Flores Coni et al. 2019). Como indicadores relativos, desde otras líneas de evidencia, se suman ciertas tecnologías como parapetos de caza y morfologías de puntas de proyectil.
${ }^{11}$ Un estudio preliminar de dos sitios de la meseta del Cardiel Chico (La Herradura 2 y Laguna Nevada) indica que superan los 200 motivos (Belardi et al. 2013).

\section{REFERENCIAS}

Acevedo, A. \& D. Fiore 2020. Imágenes, códigos y comunicación: un análisis del arte rupestre en el extremo sur del Macizo del Deseado (Patagonia, Argentina). Arqueología 26 (2): 127-155. <http://revistascientificas.filo.uba.ar/index. php/Arqueologia/article/view/5835/7205> [consultado: 04-10-2021].

Artigas, D., C. Muñoz \& V. Lucero 2016. Dame una manito: integrando el contexto del arte rupestre a la arqueología del Ibáñez Medio. En Imágenes rupestres: lugares y regiones, F. Oliva, A. M. Rocchietti \& F. Solomita Banfi, eds., pp. 559-568. Rosario: Universidad Nacional de Rosario.

Aschero, C. A. 1996. ¿A dónde van esos guanacos? En Solo Patagonia, J. Gómez Otero, ed., pp. 153-162. Puerto Madryn: CENPAT-CONICET.

BELARDI, J. B. \& R. GoÑI 2006. Representaciones rupestres y convergencia poblacional durante momentos tardíos en Santa Cruz (Patagonia Argentina). El caso de la meseta del Strobel. En Tramas en la piedra, D. Fiore \& M. M. Podestá, eds., pp. 85-94. Buenos Aires: WAC-SAA-AINA.

Belardi, J. B., S. Espinosa, G. Barrientos, F. Carballo Marina, A. Re, P. Campan, A. Súnico \& F. Guichón 2013. Las mesetas de San Adolfo y Cardiel Chico: estrategias de movilidad y tácticas de caza de guanacos en el so de Santa Cruz. En Tendencias teórico-metodológicas y casos de estudio en la arqueología de Patagonia, A. F. Zangrando, R. Barberena, A. Gil, G. Neme, M. Giardina, L. Luna, C. Otaola, S. Paulides, L. Salgán \& A. Tivoli, comps., pp. 261-270. Buenos Aires: Museo de Historia Natural de San Rafael-SAA-INAPL.

BLANCO, R. V. 2015. El arte rupestre en los macizos del Deseado y Somuncurá: la producción de grabados y pinturas entre cazadores-recolectores desde el Holoceno Medio. Tesis para optar al grado de Doctora en Ciencias Naturales, Facultad de Ciencias Naturales y Museo, Universidad Nacional de La Plata. <http://sedici.unlp.edu.ar/handle/10915/44509> [consultado: 04-10-2021].

Cabrera A. L. \& A. Willink 1980. Biogeografía de América Latina. Washington DC: OEA.

CARDEN, N. 2008. Imágenes a través del tiempo. Arte rupestre y construcción social del paisaje en la Meseta Central de Santa Cruz. Buenos Aires: Sociedad Argentina de Antropología.

CARdEN, N. \& L. MiotTi 2020. Unraveling rock art palimpsests through superimpositions: the definition of painting episodes in Los Toldos (southern Patagonia) as a baseline for chronology. Journal of Archaeological Science, Reports 30: 102-265. <https://doi.org/10.1016/j.jasrep.2020.102265> [consultado: 04-10-2021]. 
Cassiodoro, G., F. Guichón \& A. Re 2019. Diseños sobre soportes móviles y comunicación en el centro-oeste de Santa Cruz durante el Holoceno Tardío. En Arqueología de Patagonia: el pasado en las arenas, J. Gómez Otero, A. Svoboda \& A. Banegas, eds., pp. 29-40. Puerto Madryn: Instituto de Diversidad y Evolución Austral.

Cordero, R., C. MuÑoz \& D. Artigas 2019. Reinterpretando paredes: interacción e intercambio de información en el Ibáñez medio, Patagonia central, Chile. Boletín del Museo Chileno de Arte Precolombino 24 (1): 37-55. <https://boletinmuseoprecolombino.cl/wp/wp-content/uploads/2019 /06/03Cordero_19junio.pdf> [consultado: 04-10-2021].

Fiore, D. \& A. Acevedo 2016. El trabajo del arte. Una evaluación de la inversión laboral en la producción de arte rupestre: el caso del Cañadón Yaten Guajen (Santa Cruz, Patagonia, Argentina). En Imágenes rupestres: lugares y regiones, F. Oliva, A. Rocchietti \& F. Solomita Banfi, eds., pp. 485-504. Rosario: Universidad Nacional de Rosario.

Fiore, D. \& A. Acevedo 2019. El arte rupestre de la localidad Viuda Quenzana revisitado (Santa Cruz, Patagonia Argentina): nuevas evidencias y primeros resultados de análisis. Boletín del Museo Chileno de Arte Precolombino 24 (2): 11-34. <https://boletinmuseoprecolombino.cl/wp/ wp-content/uploads/2020/01/01Fiore.pdf > [consultado: 04-10-2021].

Fiore, D. \& M. OCAMPo 2009. Arte rupestre de la región margen norte del río Santa Cruz: una perspectiva distribucional. En Arqueología de Patagonia: una mirada desde el último confín, M. Salemme, F. Santiago, M. Álvarez, E. Piana, M. Vásquez \& M. E. Mansur, eds., tomo 1, pp. 499-513. Ushuaia: Editorial Utopías.

Flores Coni, J. 2018. Poblamiento humano y uso del espacio en la meseta del Strobel (Provincia de Santa Cruz). Un análisis sobre la variabilidad tecnológica durante el Holoceno. Tesis para optar al grado de Doctora en Arqueología, Facultad de Filosofía y Letras, Universidad de Buenos Aires. <https://ri.conicet.gov.ar/handle/11336/82893> [consultado: 04-10-2021].

Flores Coni, J., A. Re, A. Nuevo Delaunay, F. Guichón \& V. LANGe 2019. Múltiples evidencias, un solo lugar: el sitio K127-Vega del Flaco (Meseta del Lago Strobel, Santa Cruz). En Arqueología de Patagonia: el pasado en las arenas, J. Gómez Otero, A. Svoboda \& A. Banegas, eds., pp. 385-395. Puerto Madryn: Instituto de Diversidad y Evolución Austral.

Gilli A., F. S. Anselmetti, D. Ariztegui, M. Beres, J. MCKenZIE \& V. MARKGRAF 2005. Seismic stratigraphy, buried beach ridges and contourite drifts: the Late Quaternary history of the closed Lago Cardiel basin, Argentina ( $49^{\circ} \mathrm{S}$ ). Sedimentology 52: 1-23.

González Dubox, R., A. Frank, M. Cueto \& R. Paunero 2021. Manifestaciones rupestres situadas: tipología y distribución de las pinturas de La María Quebrada, provincia de Santa Cruz. Cuadernos del INAPL, series especiales 9 (1): 225-244.
Goñi, R., A. Re, S. García Guraieb, G. Cassiodoro, A. Tessone, D. Rindel, J. Dellepiane, J. Flores Coni, F. Guichón \& A. Agnolin 2019. Climate changes, human peopling and regional differentiation during Late Holocene in Patagonia. Quaternary International 505: 4-20.

Goñi, R., A. Re, J. B. Belardi, J. Flores Coni \& F. Guichón 2014. Un lugar muy particular. Caza, convergencia de poblaciones y circulación de información en la meseta del Strobel. En Arqueología de las cuencas de los lagos Cardiel y Strobel. Poblamiento humano y paleoambientes en Patagonia, R. Goñi, J. B. Belardi, G. Cassiodoro \& A. Re, eds., pp. 155-186. Buenos Aires: Aspha Ediciones.

Gradin, C. J. 1983. El arte rupestre de la cuenca del río Pinturas, Provincia de Santa Cruz, República Argentina. Ars Praehistorica II: 87-149.

Guichón, F. 2018. Redes de información durante el Holoceno Medio y Tardío en Patagonia meridional. Estudio de las representaciones rupestres en la cuenca del lago Cardiel y sur de la meseta del Strobel. Tesis para optar al grado de Doctor en Arqueología, Facultad de Filosofía y Letras, Universidad de Buenos Aires.

Guichón, F. \& A. Re 2020. Hunter-gatherer land use strategies and hand stencils in Southern Patagonia: a comparative analysis of the Strobel Plateau and Cardiel Lake (Argentina). Cuadernos de Arte Prehistórico, número especial 1: 122-153.

Guichón, F., A. Re, R. GoÑ \& J. Flores Coni 2016. Asignación temporal y contextualización de los grabados en mesetas altas de Santa Cruz, Argentina. En Imágenes rupestres: lugares y regiones, F. Oliva, A. Rocchietti \& F. Solomita Banfi, eds., pp. 505-516. Rosario: Universidad Nacional de Rosario.

LANCELOTTi, J. L. 2009. Caracterización limnológica de lagunas de la Provincia de Santa Cruz y efectos de la introducción de Trucha Arco Iris (Oncorhynchus mykiss) sobre las comunidades receptoras. Tesis para optar al grado de Doctor en Biología, Centro Regional Universitario Bariloche, Universidad Nacional del Comahue.

LANGe, V. \& P. TChilinguirian 2017. Distribución del registro arqueológico y recursos hídricos. Utilización de un sistema de información geográfico en la meseta del lago Strobel (Santa Cruz, Argentina). En Arqueología de Patagonia. El pasado en las arenas, J. Goméz Otero, A. Svodoba \& A. Banegas, eds., pp. 305-314. Puerto Madryn: Instituto de Diversidad y Evolución Austral.

MartínEZ, L. 2021. Las representaciones rupestres del sitio K145 - Laguna del Puente (Meseta del Strobel, Santa Cruz). Cuadernos del INAPL, series especiales 9 (1): 342-357.

Oliva, G., L. González, P. Rial \& E. Livraghi 2001. El ambiente en la Patagonia Austral. En Ganadería ovina sustentable en la Patagonia austral. Tecnologías de manejo extensivo, P. Borreli \& G. Oliva, eds., pp. 19-82. Buenos Aires: Ediciones INTA.

RE, A. 2010. Representaciones rupestres en mesetas altas de la provincia de Santa Cruz. Circulación de información 
en espacios de uso estacional. Tesis para optar al grado de Doctora en Antropología, Facultad de Filosofía y Letras, Universidad de Buenos Aires.

RE, A. 2017. Grabados de guanacos en la Patagonia austral. Intersecciones en Antropología 18: 135-147.

RE, A. \& J. B. BELARDi 2019. Pinturas rupestres y comunicación en la cuenca de los lagos Tar y San Martín (provincia de Santa Cruz). Revista del Museo de Antropología 12 (1): 73-84.

RE, A. \& F. Guichón 2009. Densidad y distribución de representaciones rupestres en la meseta del Strobel (Provincia de Santa Cruz). En Arqueología de Patagonia: una mirada desde el último confín, M. Salemme, F. Santiago, M. Álvarez, E. Piana, M. Vásquez \& M. E. Mansur, eds., tomo 1, pp. 527-540. Ushuaia: Editorial Utopías.

RE, A. \& F. Guichón 2016. Desenredando líneas. Variabilidad en grabados abstractos de Patagonia meridional. En Imágenes rupestres: lugares y regiones, F. Oliva, A. Rocchietti \& F. Solomita Banfi, eds., pp. 537-546. Rosario: Universidad Nacional de Rosario.

Re, A., R. Goñi, J. B. Belardi \& F. Guichón 2010a. Evidencias de contacto en el arte rupestre de la Meseta del Strobel (Patagonia austral argentina). En Global Rock Art. Anais do Congresso Internacional de Arte Rupestre IFRAO. Fundhamentos Ix (4), pp. 1319-1330. Piauí: Fundação Museu do Homen Americano. <https://www.academia.
edu/4451937/Evidencias_de_contacto_en_el_arte_rupestre_de_la_Meseta_del_Strobel_Patagonia_austral_argentina_> [consultado: 10-12-2021].

Re, A., F. Guichón, I. Rapela \& A. Nuevo Delaunay 2010 b. El cañadón en la meseta: análisis de las representaciones rupestres y de la tecnología lítica de El Lobo-K22 (meseta del lago Strobel, Santa Cruz). En Arqueología Argentina en el Bicentenario de la Revolución de Mayo, XVII Congreso Nacional de Arqueología Argentina, R. Bárcena \& H. Chiavazza, eds., tomo v, pp. 1963-1968. Mendoza: Universidad Nacional de Cuyo-CONICET.

Re, A., F. Guichón \& J. B. Belardi 2013-2014. Las mesetas de San Adolfo y del Cardiel Chico (provincia de Santa Cruz): su uso y jerarquización regional a partir de los motivos rupestres. Cuadernos del INAPL 23 (2): 91-106.

Re, A., R. Goñi, J. Flores Coni, F. Guichón, J. M. Dellepiane \& M. UMaÑo 2017. Arqueología de la meseta del Strobel (Patagonia meridional): 15 años después. Relaciones de la Sociedad Argentina de Antropología XLII (1): 33-58.

Re, A., F. Guichón, E. Ahets Etcheberry \& M. Rouan SIROLLI 2019. Representaciones rupestres y jerarquización del espacio al interior de la meseta del Strobel (Santa Cruz, Argentina). Sociedades de Paisajes Áridos y SemiÁridos. Revista Científica del Laboratorio de Arqueología y Etnohistoria XII (2): 90-113. 